\title{
Analysis of RNA Degradation in Dental Pulp to Estimate Postmortem Interval
}

Amanda Balasko

Follow this and additional works at: https://researchrepository.wvu.edu/etd

\section{Recommended Citation}

Balasko, Amanda, "Analysis of RNA Degradation in Dental Pulp to Estimate Postmortem Interval" (2015). Graduate Theses, Dissertations, and Problem Reports. 5146.

https://researchrepository.wvu.edu/etd/5146

This Thesis is protected by copyright and/or related rights. It has been brought to you by the The Research Repository @ WVU with permission from the rights-holder(s). You are free to use this Thesis in any way that is permitted by the copyright and related rights legislation that applies to your use. For other uses you must obtain permission from the rights-holder(s) directly, unless additional rights are indicated by a Creative Commons license in the record and/ or on the work itself. This Thesis has been accepted for inclusion in WVU Graduate Theses, Dissertations, and Problem Reports collection by an authorized administrator of The Research Repository @ WVU. For more information, please contact researchrepository@mail.wvu.edu. 


\title{
Analysis of RNA Degradation in Dental Pulp to Estimate Postmortem Interval
}

\author{
Amanda Balasko \\ Thesis submitted to the \\ Eberly College of Arts and Science \\ at West Virginia University \\ In partial fulfillment of the requirements for the degree of \\ Master of Science in \\ Biology
}

\author{
Clifton Bishop, Ph. D., Chair \\ Jennifer Hawkins, Ph. D. \\ Tina Moroose, M.S. \\ Department of Biology
}

Morgantown, WV

2015

Keywords: Forensic Science, RNA, Postmortem Interval, Polymerase Chain Reaction,
Dental Pulp

Copyright 2015 Amanda Balasko 


\section{ABSTRACT \\ Analysis of RNA Degradation in Dental Pulp to Estimate Postmortem Interval}

\section{Amanda Balasko}

There are several methods that are currently used to estimate a postmortem interval (PMI), including physiological, biochemical, entomological, and archeological approaches. However, these methods are not effective in estimating PMI's extending from several weeks to months. The study presented here was performed to create an independent, objective biological method to estimate PMI by analyzing the degradation of $18 \mathrm{~S}$ ribosomal RNA (rRNA) from porcine and human dental pulp. If successful, this method would overlap and extend the current PMI estimation methods. With a concept similar to that of radioactive carbon-14 dating, this method analyzed two different sized segments - one large, labile segment and one small, stable segment - of the same rRNA strand using real-time reverse transcription polymerase chain reaction (RT-PCR). Since the larger segment acts as a larger target for degradation forces, it is expected that the larger PCR amplicons will disappear more quickly than the smaller amplicons, and it is the difference in the quantities of each amplicon that is expected to help estimate a PMI. A multiplex reaction with a designated fluorescent marker for each larger and smaller segment was used to examine both segments of the RNA within a single sample. Teeth and weather data were collected weekly. Once the dental pulp was isolated, the RNA was extracted and converted to complimentary DNA (cDNA) using reverse transcription PCR. Once in the cDNA form, the samples were analyzed using real-time PCR. Colorimetric data was also collected by taking a picture of the pulp sample, and using Adobe Photoshop to quantify the color content of each photograph. As PMI increased, the tooth pulp experienced some color and morphological changes, as well as degradation of the rRNA target which allowed for a relative estimate of time since death with porcine samples. Using the weather data collected, accumulated degree days (ADD) for each sample were calculated and helped refine the PMI estimate. Unfortunately, the human samples were not as successful, possibly due to the age of the specimens studied. One study of an 18-year old specimen produced promising results which were similar to those obtained with the porcine samples. However, due to some resource restraints, further analyses could not be performed on younger human specimens in this particular study, though it was evident that age of the human specimens had a robust effect on the method outcome. Still, this method can be of great significance to the forensic field, especially since PMI estimates get more complicated as decomposition progresses. This method can also fill the time gap between the maximum amount of time insects can be used to estimate a PMI and the minimum amount of time archeological approaches can be applied. Determining an accurate PMI estimate is crucial to recreating a possible homicide event and will be extremely beneficial to forensic investigations. Using a technique such as the one herein may assist investigations that may not have been able to be solved before without an accurate PMI estimate. 


\section{ACKNOWLEDGEMENTS}

The completion of my thesis was the furthest thing from an independent task, and would not have been possible without any/all of the following contributors. First and foremost, I would like to thank my research advisor, Dr. Clifton Bishop, who has not only supported and encouraged me through the highs and lows, but has also given me both scientific and life guidance that I will be able to apply in my future. Your energy and enthusiasm for the field only increased mine, and encouraged me to keep going, even after multiple (and seemingly endless) obstacles. I would also like to thank my M.S. committee members Dr. Jennifer Hawkins and Tina Moroose for their support and encouragement as well. The balance of biology, genomics, and forensic advice that was constantly given to me by my committee throughout my M.S. journey has significantly increased my knowledge, research skills, enthusiasm, and desire to work in the forensic biology field and has made me an overall well-rounded scientist. I came into the WVU Biology M.S. program with set goals and all three of my committee members continued to push me and hold me accountable until I achieved them. This great feeling of accomplishment would not have been possible without any of you, so thank you.

I would also like to thank Joshua Moore, my lab partner, and Dr. Stephanie Young whose previous experience with this project allowed me to learn the techniques and knowledge needed to complete all of the research I performed in the lab. Furthermore, I would like to thank the entire WVU Biology department professors, staff, and graduate students for their collaborations, support, and advice over the past few years, especially all of those who have kept me sane throughout this entire process. Science is its own world, and nobody seems to understand that quite like your nerdy peers.

I would not have been able to continue to pursue my dreams if it were not for all of my family and friends. A special thanks to my parents and sisters who have always continued to love, encourage, and support me over the long years of education, experiences, obstacles, and triumphs. The amount of support I have received from all of my family and friends is overwhelming, and I cannot thank any of you enough. Words cannot describe how truly appreciative I am.

Most importantly, a proper acknowledgement to the National Institute of Justice for funding this project and making all of the research possible: Award \#2010-DN-BX-K247. The 
opinions, findings, and conclusions or recommendations expressed in this publication/program/exhibition are those of the author(s) and do not necessarily reflect those of the Department of Justice. 


\section{TABLE OF CONTENTS}

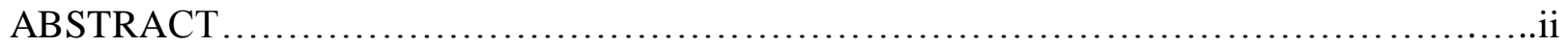

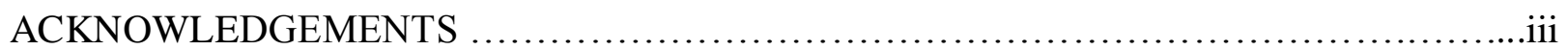

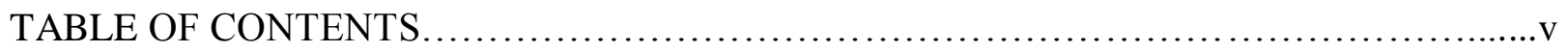

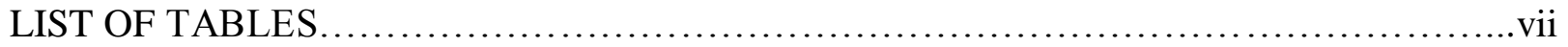

LIST OF FIGURES .................................................................

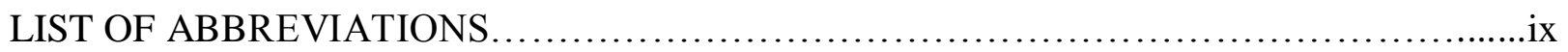

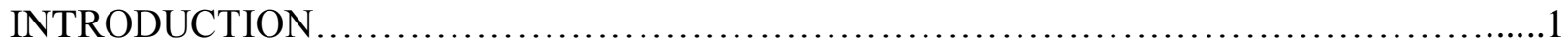

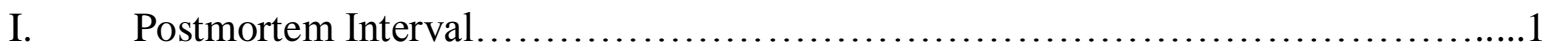

II. Ribonucleic Acid......................................................4

III. Real-time Reverse Transcription Polymerase Chain Reaction......................8

IV. Estimating Postmortem Interval Using $\beta$-actin mRNA Degradation................9

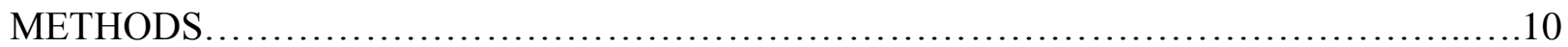

I. Porcine Samples................................................... 10

Primer/probe multiplex optimization for quantitative polymerase chain reaction .....10

Burial of pigs and sample collection ...................................... 10

RNA extraction from tooth pulp ...........................................11

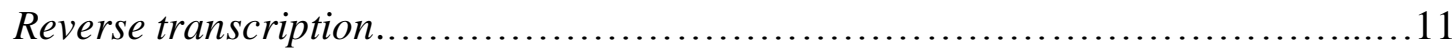

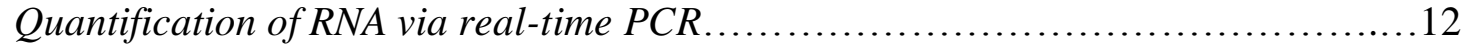

Colormetric analysis of tooth pulp ........................................ 13

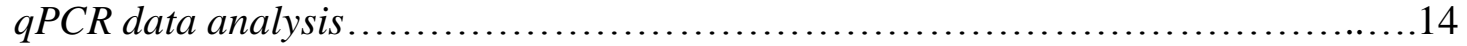

PMI estimation in ADD ......................................................... 14

PMI estimation in calendar days vs. ADD.................................... 14

II. Human Samples........................................................... 16

Primer/probe multiplex optimization for quantitative polymerase chain reaction .....16

Burial of human heads and sample collection .....................................16

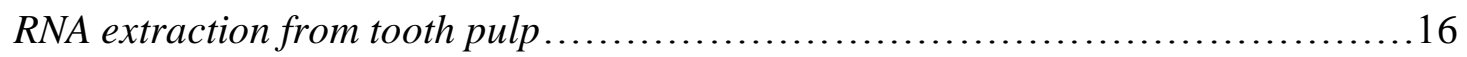

Reverse transcription ................................................... 17 
Quantification of RNA via real-time PCR................................... 17

Colormetric analysis of tooth pulp ......................................... 18

$q P C R$ data analysis ..................................................... 19

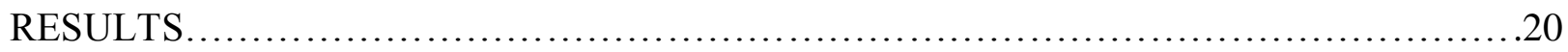

I. Porcine Samples.......................................................20

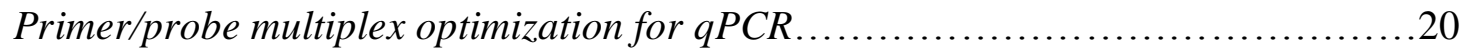

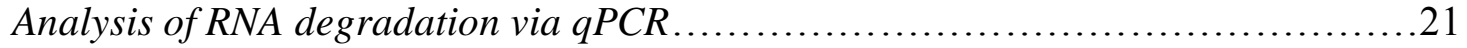

Colormetric and morphological analysis of pulp via microphotography

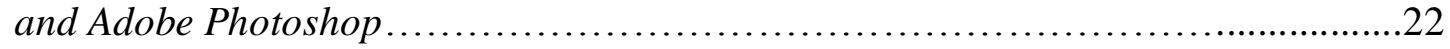

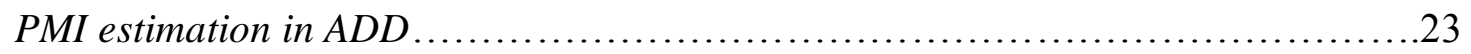

PMI estimation in calendar days vs. ADD ...................................25

II. Human Samples.........................................................29

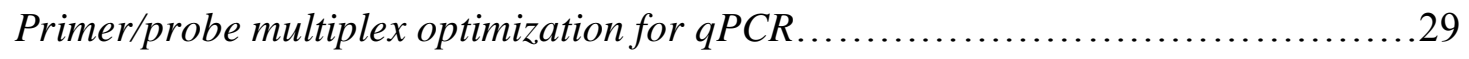

Analysis of RNA degradation via $q$ PCR ...........................................

Colormetric and morphological analysis of pulp via microphotography

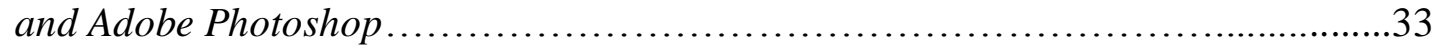

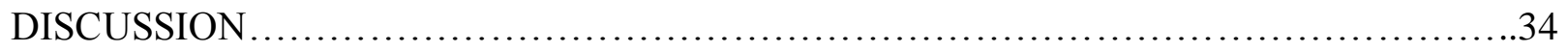

I. Porcine Samples.............................................................

II. Human Samples........................................................ 37

FINAL CONCLUSIONS....................................................41

REFERENCES.............................................................. 44 


\section{LIST OF TABLES}

Table 1. Real-time PCR Primer and Probe Sequences for Pig Samples......................12

Table 2. Real-time PCR Primer and Probe Sequences for Human Samples...................18

Table 3. Real-time PCR Forward (FP) and Reverse (RP) Final Primer Concentrations for

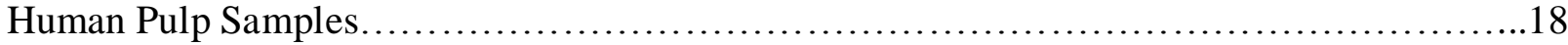

Table 4. Color content of pig pulp images grouped into 3 clusters via K-means cluster analysis.

Table 5. Mean and standard deviation values for color content in each K-means cluster.......23 


\section{LIST OF FIGURES}

Figure 1. Efficiency of the $18 \mathrm{~S} 5 / 300$ primer/probe combination for porcine RNA............20

Figure 2. Real-time PCR analysis of porcine $18 \mathrm{~S}$ rRNA degradation from dental pulp........21

Figure 3. Real-time PCR analysis of porcine 18S rRNA degradation from dental pulp in

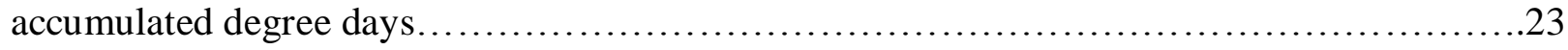

Figure 4. Production of a predictive equation to estimate PMI ............................26

Figure 5. Efficiency of the 18S 5/300, 18S B/5, and 18S 66/137 primer/probe combination for

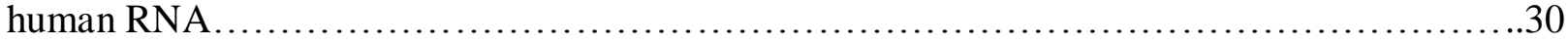

Figure 6. Real-time PCR analysis of human 18S rRNA degradation from dental pulp..........32 


\section{LIST OF ABBREVIATIONS}

\begin{tabular}{|c|c|}
\hline ACTB & Actin-beta \\
\hline ADD & Accumulated degree days \\
\hline $\mathrm{ADH}$ & Accumulated degree hours \\
\hline ADP & Adenosine diphosphate \\
\hline ANOVA & Analysis of variance \\
\hline ATP & Adenosine triphosphate \\
\hline bp & Base pair \\
\hline $\mathrm{Ct}$ & Cycle threshold \\
\hline dNTP & Deoxynucleotide triphosphate \\
\hline GAPDH & Glyceraldehyde-3-phosphate dehydrogenase \\
\hline mRNA & Messenger ribonucleic acid \\
\hline PCR & Polymerase chain reaction \\
\hline PMI & Postmortem interval \\
\hline qPCR & Quantitative polymerase chain reaction \\
\hline rRNA & Ribosomal ribonucleic acid \\
\hline RNA & Ribonucleic acid \\
\hline RT-PCR & Reverse transcription polymerase chain reaction \\
\hline tRNA & Transfer ribonucleic acid \\
\hline
\end{tabular}




\section{INTRODUCTION}

\section{Postmortem Interval}

When a crime is committed, an investigator will often try to recreate the scene or act in order to determine exactly what happened, and in order to gain information about a possible suspect, or sometimes victim. Time since death, or postmortem interval (PMI), is a crucial component of crime scene investigation, especially when there are no witnesses available. Since it is impossible to determine exactly when a body has died, estimating a PMI gives investigators a minimum and/or a maximum period of time since death, determining a relative time frame in which the body most likely died. There are several components of a decaying body that can help investigators determine how long the body has been deceased, beginning immediately after death and continuing until the body has become completely skeletonized. For early postmortem stages, pathologists can determine a short, recent PMI based on the body condition itself. Approximately 1 hour post mortem, the body will exhibit livor mortis as all the blood that was previously being pumped through the body settles to the lowest portions of the body due to gravity, and causing discoloration [1]. Moreover, when pressure is applied to areas exhibiting livor mortis, blood in the area will spread and leave the area that was pressured white until the pressure is completely removed. This occurs up to 12 hours postmortem until the livor mortis discoloration becomes fixed [1]. Additionally, after 2 hours postmortem the body will exhibit rigor mortis, or the stiffening of all muscles due to the conversion of adenosine triphosphate (ATP) to adenosine diphosphate (ADP) and production of lactic acid [1]. This chemical process decreases cellular $\mathrm{pH}$, "locking" actin and myosin interactions and forcing muscles to become inflexible. Rigor mortis typically sets in 2-6 hours postmortem and lasts up to 84 hours postmortem before the muscles finally relax [1]. Another common PMI indicator is algor mortis. About 2-3 hours after death, the body temperature will begin to approach ambient temperature at a constant rate, and will continue to decrease for about 18 hours after death when ambient temperature is reached [1]. This method of estimation, however, can be influenced by several factors including environmental temperature and mass of the victim. Other indicators of decomposition that may occur after these processes include skin slippage, mummification, saponification (hydrolysis of fatty tissue causing a waxy appearance), and putrefaction. Yet, all 
of these processes occur relatively shortly after death and are subject to time variation depending on the environment in which the body is located [1].

Unfortunately, not all bodies are found within a few hours after death. For this reason, investigators combine other areas of science in order to determine a PMI. Biochemical analysis of the vitreous humor has been confirmed to determine a PMI about 130 hours after death [2]. After death, the concentration of potassium ions within the body increases due to energy breakdown and the arrest of active transport of ions or molecules across the cellular membranes [2]. A sample of the potassium concentration can easily be extracted from the vitreous humor, especially since it is anatomically protected by the eye lids from most contamination. The measured concentration of potassium can then be entered into one of the several proposed formulas to calculate the estimated PMI [2]. However, since there are several proposed formulas and many different protocols that can be used to extract and measure the potassium concentration, there is plenty of room for error or inaccurate estimates of PMI.

As a body decomposes, the chemical and biochemical processes that are occurring not only affect the body, but also inflict changes on the surrounding environment. The volatile components a decomposing body gives off attract multiple scavengers, including birds, rodents, insects, and pets $[3,4]$. Hence, studying these scavengers may give some insight on when the person may have died. For example, entomology is the use, or study, of insects and their developmental life cycles in order to determine how much time has elapsed [5]. The most common insects of interest in these cases are blow flies, house flies, or flesh flies, but beetles and house moths have also been known to populate a decomposing corpse $[4,5]$. It is important to note, however, that the number of insects, as well as the type of insects varies by location, climate, year, and season. Still, insects have been known to feed on a corpse until no flesh remains [6]. Using entomological methods, a PMI can be estimated by determining the age or life stage of an insect feeding on the body or by identifying the species of insect on or near the body [6]. It is also important to note that insects may not immediately find or feed on the body; depending on surrounding conditions, it may take minutes or hours after death before insects are attracted to the body. When using the former method, only a minimum of time since death can usually be determined since the amount of time between deposition from the insect mother and 
discovery or collection is unknown [6]. On the other hand, if the latter method is used to estimate a PMI, a minimum PMI can be estimated depending on the type of insect species collected from the body. This is due to the fact that insects feed on a corpse in a succession, depending on how long the body has been decomposing [6].

It is also important to note that the rate of development of these insects is temperature dependent - age is positively correlated to total thermal units of the specimen [7]. Therefore, it is common practice to calculate the accumulated degree hours $(\mathrm{ADH})$ or accumulated degree days (ADD) of an insect sample. ADD is also commonly used in agriculture and simply takes daily temperatures into account and applies study specific thresholds to determine the amount of thermal units applied to the unit being examined [7]. Still, there are several different procedures and developmental thresholds applied when studying each insect life cycle, and thus, there is much room for error. Because of this, PMI estimates are often given in large time intervals and may increase the chance of overestimating the exact PMI of a body, which may even change the direction of the investigation [5].

For even further extended periods of time, an archeological approach can be taken to determine a PMI for bodies that have been dead or decomposing for several years. The most common method with this approach is to use radiocarbon dating on human bones, much like geologists would with other organic material found in the earth's soil. Measuring concentrations of radioactive carbon-14 is a very reliable method of dating a bone. The ratio of the amounts of radioactive carbon-14 and nonradioactive carbon-12 are used to estimate the age of a bone. However, this method can only determine if a bone is an archeological artifact, or if it is actually beneficial to a forensic investigation [8]. Dating human remains with ${ }^{14} \mathrm{C}$ allows a sample to be categorized in one of the three main temporal divisions: non-modern (before 1650), pre-modern (1650-1950), and modem (1950 to present) [8]. Clearly, this is not always the best method to determine a PMI for a recent investigation, since the half-life of ${ }^{14} \mathrm{C}$ is about 5,730 years.

As evident by the examples given, there is a huge time gap between the time of death of a victim and the time of discovery of the body that is not covered by any of the common methods. In order to fill this time gap, some studies have attempted to use chemical or 
biological techniques to reliably estimate a PMI. Vass et al. (2002) characterized different chemical components of a decomposing body and attempted to use biomarker analysis to estimate a PMI [9]. With his method, Vass was able to determine distinct amino acids, neurotransmitters, and decompositional by-products that were unique to different body tissues postmortem. However, with methods such as these, variation in chemical components can be dependent on the environment, the victim's diet, victim's body mass, and other factors. Hence, some studies, including the one herein, are taking a more biological approach.

With increasing advances in molecular biology in the past few decades, forensic scientists are relying more heavily on the field in order to study and even solve different aspects of a forensic investigation that may not have been able to be examined before. In this regards, Johnson et al. examined DNA degradation and fragmentation patterns in postmortem human leukocytes via single-cell gel electrophoresis [10]. However, it is important to note that DNA is so stable that it may take thousands of years to completely degrade. For this special reason, DNA has been used to date bone samples that range from 5,500 to 47,000 years old [11, 12]. Yet, for this same reason, DNA is not necessarily ideal for estimating a more recent PMI. Because of this, studies have focused on measuring the amount of RNA in a postmortem biological sample in order to determine a range of time in which a body may have died [14, 15]. RNA degrades at a faster rate than DNA due to ribonuclease activity that occurs postmortem, its increased sensitivity to changes in $\mathrm{pH}$, and possibly the creation of free radicals, all of which may make RNA more useful for relatively recent PMI estimates [15]. No matter how it is determined, estimating an accurate PMI is crucial to recreating a possible homicide event, and is extremely beneficial to forensic investigations.

\section{Ribonucleic Acid}

Ribonucleic acid (RNA) is typically a single stranded nucleic acid molecule that is becoming increasingly important in the forensic field. RNA is abundant in all cell types and exhibits a relatively quick degradation process compared to deoxyribonucleic acid (DNA), which takes several years to fully degrade without any external interference. Because of this, RNA has been beneficial in identifying body fluids found at a crime scene, determining the age of a body fluid stain, and determining a postmortem interval $[16,17]$. After death, RNA is 
known to degrade rapidly due to ribonuclease activity, but can also be affected by factors such as microbial or bacterial activity, $\mathrm{pH}$, temperature, and possibly free radicals [17]. As expected, it has been found that tissues and organs, such as the liver, that contain greater amounts of ribonucleases will exhibit faster RNA degradation. On the other hand, tissues that contain lower amounts of ribonucleases, like the brain, will exhibit slower RNA degradation [17]. In addition, the manner of death may also have an effect on the degradation of the RNA depending on the tissue type [17].

The type of RNA present in different tissue types depends on the function of the tissue itself. With this in mind, some studies have used different RNA targets to identify body fluids or tissues collected from a crime scene, including blood, semen, saliva, menstrual blood, and vaginal secretions [18-25]. RNA is beneficial due to its specificity and sensitivity, allowing for body fluid identification down to $1 \mu \mathrm{L}$ of saliva, $0.1 \mu \mathrm{L}$ of semen, and $10^{-5} \mu \mathrm{L}$ of blood via polymerase chain reaction (PCR) [26]. Hence, using RNA as a means to identify body fluids overcomes the possibility of cross-reaction false positive results that may occur with common presumptive tests performed at the crime scene that are typically dependent on enzymatic activity of the respective tissue [26]. For similar reasons, RNA isolation presents the possibility of a multiplex reaction, allowing for the identification of multiple body fluids within one reaction [17]. It has also been determined that RNA isolation of body fluids still allows for simultaneous isolation of DNA for identification purposes, making this an extremely beneficial technique for crime scene investigation $[27,28]$.

In addition, under semi-controlled conditions, RNA can remain stable for extended periods of time. For example, RNA was able to be extracted from dried blood stains on filter paper after several weeks [29, 30], on glass slides after 2 years [30, 31], and on cotton fabric after 16 years of storage $[13,33]$ for various virological, genetic, and forensic purposes. Although postmortem RNA continuously degrades, its concurrent relative stability has allowed studies to estimate the age of bloodstains $[13,16]$. The isolation of DNA from a biological stain allows for the determination of the contributor, but does not necessarily provide information as to when the sample was deposited. Therefore, using RNA to estimate when the stain may have been left at a scene provides a critical component to a forensic investigation, placing the 
contributor at the scene or the crime within a specific time frame. By measuring the extent of RNA degradation via PCR, studies have been able to estimate when a biological stain was deposited on various materials [17].

Similarly taking advantage of these unique characteristics of RNA, other studies, including the one herein, have been able to measure the amount of RNA in postmortem tissue samples in order to determine a postmortem interval (PMI). Zhao et al. noticed a PMI dependent change in the amount of RNA transcript in human heart, brain, kidney, and lung tissue over a 72 hour period [34]. Additionally, Inoue et al. measured significant differences in the amount of glyceraldehyde-3-phosphate dehydrogenase (GAPDH) messenger RNA (mRNA) at different PMIs over a 7 day period in rat brain, heart, lung, and liver tissues [35]. In a similar manner, Bauer et al. measured the fragmentation level of fatty acid synthase-messenger RNA (FASN-mRNA) from human blood and brain samples stored from 7 to 145 hours postmortem [13]. Though beneficial, these studies only analyzed samples with relatively short PMIs. Therefore, in an attempt to predict and extend a PMI estimate, Sampaio-Silva et al. measured RNA transcript levels in mice heart, femoral quadriceps, and liver tissue samples, and produced a mathematical equation to predict extended PMIs using known variables [36].

The most common RNA targets for each of the previously stated purposes is housekeeping gene RNAs. Housekeeping genes are necessary for typical cell function and growth, and are therefore present in all cell and tissue types [37]. These housekeeping genes are also present in variable, yet ample amounts in respective tissues, making analysis of the desired target more efficient. Moreover, it has be shown that housekeeping genes are generally expressed and conserved more than tissue specific genes [37]. There are three main types of RNAs - transfer RNA (tRNA), messenger RNA (mRNA), and ribosomal RNA (rRNA) - each of which have a particular function within the cell, and are therefore hypothesized to degrade at different rates. In this context, Bahar et al. measured total RNA levels from postmortem bovine liver, adipose, and skeletal tissues, noticing that generally $18 \mathrm{~S}$ rRNA was the most stable RNA found in each tissue [38]. Furthermore, it was found that 28S and 18S rRNA were present only up to 24 hours postmortem in liver and adipose tissue, but up to 8 days in skeletal muscle. On the other hand, GAPDH and actin-beta (ACTB) mRNA were still present in skeletal muscle 
after 22 days postmortem [38]. Uddin et al. also found that RNA levels differed between tissues types as well as ages of the donors when isolated from 1 day to 5 month old pig blood, lymph nodes, intestines, stomach, liver, spleen, thymus, heart, lung, kidney, and skin [39].

The present study uses the rate of degradation of $18 \mathrm{~S}$ rRNA isolated from dental pulp in order to determine a postmortem interval of pig and human specimens. As a housekeeping gene, $18 \mathrm{~S}$ assists in ribosomal synthesis and is therefore abundant in all cell types. As evident by previously discussed studies, though prevalent, the amount of RNA within an individual specimen depends on tissue type, age, general health, and possibly manner of death [39-41, 43]. Because of this, the amount of two non-overlapping segments of the same $18 \mathrm{~S}$ rRNA molecule was analyzed in each sample: one large, labile segment and one smaller, more stable segment. The ratio of quantities was then used to measure the extent of RNA degradation using a method similar to radioactive dating. Radioactive dating of an organic material measures the amount of a less stable radioactive carbon-14 isotope present to that of a more stable non-radioactive carbon-12. Similarly, it is expected that the larger $18 \mathrm{~S}$ segment will be less stable, acting as a larger target for degradation forces, and will therefore degrade at a quicker rate than the smaller $18 \mathrm{~S}$ segment. The different decay rates of each segment will then allow for a PMI estimate to be made. A multiplex reaction with a designated fluorescent marker for each (larger and smaller) segment was used to examine both segments of these RNAs within a single sample. It is expected that since both segments are from the same RNA molecule, the amount of both the small and large amplicons will be equivalent at day zero, or day of death. Multiplexing also assists in preventing errors such as pipetting errors or differences in enzyme efficiency [16, 43$]$.

Porcine and human dental pulp were chosen as the source of RNA for this study. Though RNA amounts and decay rates are tissue dependent, tooth pulp was expected to be a reliable source of RNA since the pulp itself it physically protected by the jaw bone and tooth enamel. In addition, the tooth and jaw bone typically decompose at a slower rate compared to other tissues in the body [1]. This further allows the dental pulp to be protected from scavengers or environmental factors, such as weather conditions, humidity, temperature, and UV light, for an extended period of time, possibly allowing for an extended PMI estimate. Moreover, 
individual teeth allow for individual unit extractions, preventing possible contamination of other tissue samples.

In addition to RNA degradation analysis, this study also quantitatively measured morphological changes in dental pulp by quantifying the color content of samples at different PMIs. Duffy et al. noticed that as PMI increased, the dental pulp also underwent morphological changes in pig and human tooth samples [42]. Though this method of analysis cannot be reliably used alone to estimate a PMI, it does help increase the accuracy of the estimate when supplemented with RNA analysis via PCR.

\section{Real-time Reverse Transcription Polymerase Chain Reaction}

The goal of the present study was to use the rate of RNA degradation in dental pulp as a means to estimate a postmortem interval in porcine and human specimens. Since the amount of RNA present in each individual sample varies depending on the specimen health and age, a ratio of a large, labile segment and a small, stable segment of the same $18 \mathrm{~S}$ rRNA molecule was measured in each sample. Before the amount of RNA could be measured, the RNA extracted from each pulp sample was converted to complementary DNA (cDNA) via reverse transcription. The single stranded RNA is converted to double stranded cDNA by synthesizing the cDNA strand in the 5' to 3' direction from the RNA template. Once in the cDNA form, the samples could be analyzed using real-time polymerase chain reaction (PCR). Real-time PCR monitors the generation of PCR amplicons as the process is occurring, typically through detection of a fluorescent marker that is bound to the cDNA strand. The probe that is used in each reaction also contains a quencher that prevents the marker from fluorescing. As the cDNA is amplified, Taq polymerase releases the quencher from the probe releasing a fluorescent signal. Results from real-time PCR analysis show the relationship between the amount of cDNA present and the amount of fluorescence detected. To measure the amount of both the small and large $18 \mathrm{~S}$ rRNA segments within each sample, a multiplex reaction was created. A designated probe for each segment size was fluorescently labeled with either FAM (larger amplicons; emission wavelength $520 \mathrm{~nm}$ ) or VIC (smaller amplicons; emission wavelength $552 \mathrm{~nm}$ ) in order to measure the amount of each segment in a single reaction. 
Theoretically, the amount of cDNA in the sample doubles with every PCR cycle. The cycle number in which fluorescence is first detected for the amplified RT-PCR product of target RNA is known as the $\mathrm{Ct}$ value for the sample. The change in the amount of fluorescence is monitored with each cycle in order to create a sigmoidal amplification curve. A threshold is set during the exponential phase of the curve, when the PCR efficiency is at $100 \%$, to give a specific $\mathrm{Ct}$ value for each sample. The $\mathrm{Ct}$ values can then be compared to determine how much cDNA is present.

\section{Estimating Postmortem Interval Using $\beta$-actin mRNA Degradation}

Previous work performed by Stephanie Young, Ph. D. set the precedent for the study presented herein [43]. Using the same methods, Young was able to use the degradation of $\beta$ actin mRNA and dental pulp morphological changes to estimate a PMI for porcine specimens. In her study, Young analyzed the difference in decay rates of a $71 \mathrm{bp}$ and a $301 \mathrm{bp}$ segment of the $\beta$-actin mRNA molecule. As PMI increased, there was a general decreasing trend in the amount of $\beta$-actin mRNA present in porcine dental pulp over an 84 day postmortem period. In addition, colormetric analysis via Adobe Photoshop and cluster analysis with SAS JMP v. 8, showed that as PMI increased, the red, blue, and green color content of the pulp changed and samples were able to be clustered into 3 main clusters, depending on color content and PMI. Samples with a PMI of 0, 7, 14, and 21 days had intermediate values of red and low intensity values for blue and green. On the other hand, samples with a PMI of 28 and 42 days had high values for all three colors, and samples with a PMI of 56, 70, and 84 days had low red values and intermediate blue and green intensity values.

Since temperature has an obvious effect on the rate of RNA degradation, Young also estimated a PMI by taking thermal units into consideration. For samples collected in summer and winter months, Young calculated the accumulated degree days (ADD) of each sample and compared them across seasons. Using a multiple regression, Young determined that calculating ADD may be a more reliable method of estimation, and even suggests an accurate estimate can be made independent of season [44]. In addition, using another multiple regression, Young was able to produce season-dependent equations to estimate a PMI with a 95\% confidence interval. Success of Young's study provided guidance for the methodology of the present study. 


\section{METHODS}

\section{Porcine Samples}

Primer/ probe multiplex optimization for quantitative polymerase chain reaction

Before applying the primer combinations to pulp samples, the multiplexing efficiency of the combination was analyzed as suggested by Livak and Schmittgen [45]. RNA-specific primer and probe sets were created using Primer3 software v. 4.0 and synthesized by Applied Biosystems (Foster City, CA). A serial dilution of porcine cDNA was created from a $525 \mathrm{ng} / \mu \mathrm{L}$ stock sample. A master mix was created from forward and reverse primers, a TaqMan TAMRA VIC-labeled probe (Applied Biosystems) for the smaller segments, a TaqMan TAMRA FAMlabeled probe (Applied Biosystems) for the larger segments, Applied Biosystems Universal PCR Master Mix (solution containing AmpliTaq Gold DNA polymerase, dNTPs, a passive reference, and buffer), and nuclease free water. Concentrations of each reagent and the conditions for the Applied Biosystems 7300 Sequence Detection System were adjusted until efficiency was achieved. qPCR cycle threshold $(\mathrm{Ct})$ values were analyzed on a $2^{-\Delta \mathrm{Ct}}$ scale [45] and were plotted against the log of serial cDNA dilutions. A primer combination was deemed efficient if the absolute value of the resulting slope was approximately zero. All optimized primer combinations are given in Table 1.

\section{Burial of pig heads and sample collection}

Freshly butchered pig heads were obtained from Emerick Meat and Packing in Hyndman, PA, and were transported to the West Virginia University Plant and Soil Sciences Farm. At the farm, the pig heads were buried in a shallow grave in a shaded area. When samples were not being collected, chicken wire and tree logs were used to cover the graves to protect the heads from scavengers. Teeth were collected from 11 different pigs across all seasons from November 2013 to October 2014. A hammer, screw driver, and pliers were used to pull the teeth from the rigid gums. Any teeth that were visibly damaged were not used in this study. Approximately once a week, teeth were isolated from the pig heads, were brought back to the lab to be washed with soap and deionized water, and were stored at $-80^{\circ} \mathrm{C}$ to allow them to 
become brittle. The weather conditions and temperature for the day of collection were also noted.

\section{RNA extraction from tooth pulp}

Individual teeth were placed in a ceramic mortar and struck with a pestle to expose the pulp. Once exposed, forceps were used to transfer a sample of pulp to a glass tissue grinder, containing $350 \mu \mathrm{L}$ of TRI-Reagent RT (Molecular Research Center, Cincinnati, OH). The pulp was ground until clumps were no longer present. The sample was then transferred to a sterile $1.5 \mathrm{~mL}$ tube containing $650 \mu \mathrm{L}$ TRI-Reagent RT. After centrifugation at 12,000 x g and $4{ }^{\circ} \mathrm{C}$ for $10 \mathrm{~min}$, the supernatant was transferred to a new $1.5 \mathrm{~mL}$ tube. To each sample, $50 \mu \mathrm{L}$ of 4 bromanisole (BAN) (Molecular Research Center) was added as a phase separator and vortexed for $15 \mathrm{~s}$. The samples were centrifuged (same as above) for $15 \mathrm{~min}$, then the aqueous phase of the sample was removed and placed into new $1.5 \mathrm{~mL}$ tube. To each sample, $500 \mu \mathrm{L}$ of cold isopropanol was then added. The samples were inverted to mix before being incubated at room temperature for $8 \mathrm{~min}$ and centrifuged (same as above) for $5 \mathrm{~min}$. The supernatant was removed and discarded before the samples were washed with $75 \%$ ethanol. After being centrifuged for 5 min, the ethanol was removed and the pellets were left to air dry under the fume hood for 5-10 min before being resuspended by $40 \mu \mathrm{L}$ of nuclease free water (Fisher Scientific, Pittsburgh, PA) and heated for $10 \mathrm{~min}$ at $55^{\circ} \mathrm{C}$.

\section{Reverse transcription}

An Applied Biosystems Taqman Gold Reverse RT-PCR kit was used to reverse transcribe the single stranded RNA samples to double stranded cDNA. A reaction mix of 1X Taqman buffer A, $2.5 \mu \mathrm{M}$ random hexanes, $5.5 \mathrm{mM}$ magnesium chloride, and $500 \mu \mathrm{M}$ dNTPs was created and $57 \mu \mathrm{L}$ aliquots were placed into $0.5 \mathrm{~mL}$ tubes. To each tube, $2 \mu \mathrm{L}$ RNase inhibitor $(0.8 \mathrm{U}), 2.5 \mu \mathrm{L}$ reverse transcriptase $(3.25 \mathrm{U})$, and $5 \mu \mathrm{L}$ nuclease free water was added, as well as $35 \mu \mathrm{L}$ of RNA sample. The samples were centrifuged for a few seconds and placed into a Techne Touchgene Gradient thermocycler (Burlington, NJ) under the following conditions: $25^{\circ} \mathrm{C}$ for $10 \mathrm{~min}, 48^{\circ} \mathrm{C}$ for $30 \mathrm{~min}$, and $95^{\circ} \mathrm{C}$ for $5 \mathrm{~min}$. 
Quantification of RNA via real-time PCR

RNA-specific primer and probe sets were created using Primer3 software v. 4.0 and synthesized by Applied Biosystems (Foster City, CA) in order to amplify distinct, nonoverlapping regions of $18 \mathrm{~S}$ rRNA. Primer combination 18S 5/300, targets a 66 bp and a $301 \mathrm{bp}$ segment of the same 18S rRNA molecule (sequences in Table 1). All multiplex primer combinations were deemed efficient according to [44] before use. A master mix solution was created to run in a multiplex reaction, consisting of the following final concentrations: $50 \mathrm{nM}$ 18S5 forward primer, $100 \mathrm{nM}$ 18S5 reverse primer, $500 \mathrm{nM}$ 18S300 forward and reverse primers, $250 \mathrm{nM}$ TaqMan TAMRA VIC-labeled probe for the smaller segments, $250 \mathrm{nM}$ TaqMan TAMRA FAM-labeled probe for the larger segments, Applied Biosystems Universal PCR Master Mix, and nuclease free water. A final volume of $24 \mu \mathrm{L}$ of master mix was added to a PCR tube with $1 \mu \mathrm{L}$ of sample cDNA. The real-time PCR reaction for each sample was run in duplicates, and each plate contained a positive control with master mix and porcine cDNA (525 $\mathrm{ng} / \mu \mathrm{L}$ ), and two negative controls - one containing master mix and nuclease free water and the other containing just nuclease free water. The samples were analyzed using an Applied Biosystems Prism 7300 Sequence Detection System under the following conditions: 1 cycle 50 ${ }^{\circ} \mathrm{C}$ for $2 \mathrm{~min}, 1$ cycle $95^{\circ} \mathrm{C}$ for $10 \mathrm{~min}$, and 40 cycles alternating between $95{ }^{\circ} \mathrm{C}$ for $15 \mathrm{~s}$ and 60 ${ }^{\circ} \mathrm{C}$ for 3 min.

Table 1. Real-time PCR Primer and Probe Sequences for Pig Samples

\begin{tabular}{ccl}
\hline Name & Segment Size Amplified (bp) & \multicolumn{1}{c}{ Primer/Probe Sequence } \\
\hline 18 S5 & 66 & FP: GAATTGACGGAAGGGCACC \\
& RP: AGGTTTCCCGTGTTGAGTCAAATTA \\
& VIC: CCAGGAGTGGAGCCTGCGGC \\
18 S300 & FP: GGCGGCTTTGGTGACTCTAG \\
& RP: GGATTTAAAGTGGACTCATTCCAATT \\
& & FAM: CGATGGTAGTCGCCGTGCCTACCA \\
\hline
\end{tabular}




\section{Colormetric analysis of tooth pulp}

Once exposed, a portion of the pulp was photographed using a Leica S6D microscope and Leica DFC450 camera with Leica Application Suite 4.4 software (Grove Village, IL). Pure red, blue, and green standards were placed next to each pulp sample to normalize any lighting variation. Each photograph was taken under the following conditions: exposure at $40.4 \mathrm{~ms}$, gain at $1 \mathrm{X}$, saturation at 1.20 , and gamma at 0.43 .

Images of the pulp were analyzed using Adobe Photoshop CC Version 14.2.1 (Adobe Systems Incorporated, San Jose, CA) to quantify the color intensity of the red, blue, and green pigments present by randomly selecting 3 pixels on the pulp sample. The values obtained were compared to the color standards to normalize any lighting variations. Pure red, blue, or green was determined by an intensity value of 255 for the respective color but 0 for the other two. Correction factors were applied to each image by accounting for color standard pixel deviation from pure red, blue, or green. For instance, the standard for green (GS) in one image will provide an intensity value for red $\left(\mathrm{GS}_{\mathrm{R}}\right)$, blue $\left(\mathrm{GS}_{\mathrm{B}}\right)$, and green $\left(\mathrm{GS}_{\mathrm{G}}\right)$. To determine the correction factor for green (GCF), all of these values must be taken into account:

$$
\begin{aligned}
& \mathrm{GCF}_{\mathrm{G}}=255-\mathrm{GS}_{\mathrm{G}} \\
& \mathrm{GFC}_{\mathrm{R}}=0-\mathrm{GS}_{\mathrm{R}} \\
& \mathrm{GFC}_{\mathrm{B}}=0-\mathrm{GS}_{\mathrm{B}}
\end{aligned}
$$

The correction factors for red and blue were calculated in a similar manner. Therefore, to determine the green corrected estimate for each pulp sample (Sample ${ }_{\mathrm{G}}$ ), the sum of the correction factors and observed intensity value $\left(\mathrm{G}_{\mathrm{obs}}\right)$ for green was calculated as follows:

$$
\text { Sample }_{\mathrm{G}}=\mathrm{G}_{\mathrm{obs}}+\mathrm{GCF}_{\mathrm{G}}+\mathrm{GCF}_{\mathrm{R}}+\mathrm{GCF}_{\mathrm{B}}
$$

The calculation was repeated for the red and blue pigments in each sample image. The average intensity values for each color from each tooth were analyzed via k-means cluster analysis $(\mathrm{k}=3)$ performed on SAS JMP v. 11 (SAS Institute Inc., Carry, NC) to determine statistical similarities between samples with differing postmortem intervals. 
qPCR data analysis

Cycle threshold values for each sample were obtained by setting qPCR baselines and thresholds according to Applied Biosystems' recommendations, which were kept constant for each run. Once all $\mathrm{Ct}$ values were obtained, the data was transferred to Microsoft Excel 2013 (Microsoft Corporation, Redman, WA) for further analysis. Ct values 35 or above indicate the presence of 1-0 copies of target RNA [46, 47], and were therefore excluded from analysis. In addition, since each sample was run in duplicate, any sample duplicate that had a difference in $\mathrm{Ct}$ values 1 (reported machine error) or greater were also excluded. For the remaining sample $\mathrm{Ct}$ values, $\Delta \mathrm{Ct}$ was calculated by subtracting the $\mathrm{Ct}$ value of the smaller amplicon (66 bp) from the larger amplicon (301 bp). The resulting values were converted to $2^{-\Delta \mathrm{Ct}}$ values [45], taking into account the fact that $\mathrm{Ct}$ values are measured on a logarithmic scale.

\section{PMI estimation in ADD}

Weather data was obtained during the period of collection from the local weather station KMGW located approximately 1 mile from the field site at the Morgantown Municipal Airport, Morgantown, WV. Once obtained, all data was uploaded to Microsoft Excel for further analysis.

Using the weather data recorded, accumulated degree days (ADD) were calculated for each sample. ADD is a measurement of thermal units that can be determined by subtracting a designated lower threshold from the mean daily temperature:

$$
\mathrm{ADD}=\left(\frac{\text { maximum daily temp }+ \text { minimum daily temp }}{2}\right)-\text { lower threshold }
$$

In this case, the lower threshold is set at $0{ }^{\circ} \mathrm{C}$ since it is assumed that limited to no enzymatic action is occurring at a freezing temperature.

\section{PMI estimation in calendar days vs. ADD}

SAS JMP v. 11 was used to perform a multiple regression to determine whether a PMI estimate would be more accurate if estimated in calendar days or in ADD, taking both RNA

degradation ( $2^{-\Delta \mathrm{Ct}}$ values) and color content into account. Factors for each model included: 
season; $2^{-\Delta \mathrm{Ct}}$; red color; green color; blue color; pig nested within season: pig (season); tooth nested within pig: tooth (pig (season)); season crossed with $2^{-\Delta \mathrm{Ct}}$ : (season $* 2^{-\Delta \mathrm{Ct}}$ ); season crossed with red color: (season*red color); season crossed with green color: (season*green color); and season crossed with blue color: (season*blue). All nested factors were designated as random, while all other factors were designated as fixed. A multiple regression was performed with these factors for both calendar days and $\mathrm{ADD}$, comparing the $\mathrm{R}^{2}$ values to determine which $\mathrm{PMI}$ measurement had the greater predictive power.

SAS JMP v. 11 was also used to formulate a predictive equation that included all known factors, such as RNA degradation and color content. A multiple regression was again performed using the predictive $\mathrm{x}$-variables $2^{-\Delta \mathrm{Ct}}$, red, green, and blue, and setting the $\mathrm{y}$-variable to be predicted as ADD. An analysis of variance (ANOVA) was also conducted on the models to determine which factors significantly affected the PMI estimate. 


\section{Human Samples}

Primer/ probe multiplex optimization for quantitative polymerase chain reaction

Before applying the primer combinations to pulp samples, the multiplexing efficiency of the combination was analyzed as suggested by Livak and Schmittgen [45]. RNA-specific primer and probe sets were created and optimized the exact same way as the porcine primer and probe sets. Blood samples were obtained from live, healthy human volunteers using a protocol approved by the West Virginia University Institutional Review Board for Protection of Human Research Subjects. A primer combination was deemed efficient if the absolute value of the resulting slope was approximately zero. All optimized primer combinations are given in Table 2.

\section{Burial of human heads and sample collection}

Human heads were obtained from the West Virginia University Human Gift Registry and were transported to the West Virginia University Plant and Soil Sciences Farm. When received, the human specimens had already been dead for 1-3 days. Age, gender, day of death, and reason of death were collected for each specimen. In a secluded, shaded area at the farm, a locked metal fence was placed around designated graves to keep out any scavengers or trespassers. The heads were individually placed in $18 \mathrm{~L}$ x $12 \mathrm{~W}$ x $14 \mathrm{H}$ " metal dog cages and buried in a shallow grave within the fence. Teeth were collected from 16 different humans across all seasons from May 2013 to November 2014. A hammer, screw driver, and pliers were used to pull the teeth from the rigid gums. Any teeth that were visibly diseased were not used in this study. Teeth with any dental work were still collected for possible extraction. Approximately once a week, teeth were isolated from the heads, were brought back to the lab to be washed with soap and deionized water, and were stored at $-80^{\circ} \mathrm{C}$ to allow them to become brittle.

RNA extraction from tooth pulp

Individual teeth were placed in a ceramic mortar and struck with a pestle to expose the pulp. RNA was extracted from the pulp following the same protocols that were performed on the porcine samples. 


\section{Reverse transcription}

An Applied Biosystems Taqman Gold Reverse RT-PCR kit was used to reverse transcribe the single stranded RNA samples to double stranded cDNA the same exact way as the porcine samples.

\section{Quantification of RNA via real-time PCR}

RNA-specific primer and probe sets were created using Primer3 software v. 4.0 and synthesized by Applied Biosystems (Foster City, CA) in order to amplify distinct, nonoverlapping regions of $18 \mathrm{~S}$ rRNA. Primer combination 18S 5/300, targets a 66 bp and a 301 bp segment, while combination $18 \mathrm{~S} \mathrm{~B} / 5$ targets a $66 \mathrm{bp}$ and a $171 \mathrm{bp}$ segment, $18 \mathrm{~S} \mathrm{~A} / \mathrm{B}$ targets a $171 \mathrm{bp}$ and $501 \mathrm{bp}$ segement, and 18S 66/137 targets a $66 \mathrm{bp}$ and a $137 \mathrm{bp}$ segment of the same 18S rRNA molecule (sequences in Table 2). All multiplex primer combinations were deemed efficient according to [44] before use. A master mix was created for each primer combination consisting of the respective final concentrations of forward and reverse primers given in Table 3, $250 \mathrm{nM}$ TaqMan TAMRA VIC-labeled probe for the smaller segment, $250 \mathrm{nM}$ TaqMan FAM-labeled probe for the larger segment, Applied Biosystems Universal PCR Master Mix, and nuclease free water. A final volume of $20 \mu \mathrm{L}$ of $18 \mathrm{~S} 66 / 137$ and $18 \mathrm{~S} \mathrm{~B} / 5$ master mix was respectively added to $5 \mu \mathrm{L}$ of sample cDNA. On the other hand, a final volume of $24 \mu \mathrm{L}$ of $18 \mathrm{~S}$ $5 / 300$ master mix was added to $1 \mu \mathrm{L}$ of sample cDNA, while a final volume of $20 \mu \mathrm{L}$ of $18 \mathrm{~S}$ A/B master mix was added to $1 \mu \mathrm{L}$ of sample cDNA and $4 \mu \mathrm{L}$ of nuclease free water. The realtime PCR reaction for each sample was run in duplicates, and each plate contained a positive control with master mix and human blood cDNA, and two negative controls - one containing master mix and nuclease free water and the other containing just nuclease free water. The samples were analyzed using an Applied Biosystems Prism 7300 Sequence Detection System under the following conditions for $18 \mathrm{~S} 5 / 300,18 \mathrm{~S} \mathrm{~B} / 5$, and $18 \mathrm{~S} 66 / 137$ samples: 1 cycle $50{ }^{\circ} \mathrm{C}$ for $2 \mathrm{~min}, 1$ cycle $95^{\circ} \mathrm{C}$ for $10 \mathrm{~min}$, and 40 cycles alternating between $95^{\circ} \mathrm{C}$ for $15 \mathrm{~s}$ and $60{ }^{\circ} \mathrm{C}$ for 3 min. The qPCR conditions for $18 \mathrm{~S} \mathrm{~A} / \mathrm{B}$ were as follows: 1 cycle $50{ }^{\circ} \mathrm{C}$ for $2 \mathrm{~min}, 1$ cycle $95^{\circ} \mathrm{C}$ for $10 \mathrm{~min}$, and 40 cycles alternating between $95^{\circ} \mathrm{C}$ for $15 \mathrm{~s}$ and $60{ }^{\circ} \mathrm{C}$ for $2.5 \mathrm{~min}$. 
Table 2. Real-time PCR Primer and Probe Sequences for Human Samples

\begin{tabular}{|c|c|c|}
\hline Name & Segment Size Amplified (bp) & Primer/Probe Sequence \\
\hline $18 \mathrm{~S} 5$ or & 66 & FP: GAATTGACGGAAGGGCACC \\
\hline \multirow[t]{2}{*}{$18 \mathrm{~S} 66$} & & RP: AGGTTTCCCGTGTTGAGTCAAATTA \\
\hline & & VIC: CCAGGAGTGGAGCCTGCGGC \\
\hline \multirow[t]{3}{*}{$18 \mathrm{~S} 137$} & 137 & FP: GTGCATGGCCGTTCTTAGTT \\
\hline & & RP: GAACGCCACTTGTCCCTCTA \\
\hline & & FAM: GTGGAGCGATTTGTCTGGTT \\
\hline \multirow[t]{4}{*}{ 18SB } & 171 & FP: CGGAGAGGGAGCCTGAGAA \\
\hline & & RP: CTCCAATGGATCCTCGTTAAAGG \\
\hline & & FAM: CGGCTACCACATCCAAGGAAGGCA \\
\hline & & VIC: CGGCTACCACATCCAAGGAAGGCA \\
\hline \multirow[t]{3}{*}{$18 \mathrm{~S} 300$} & 301 & FP: GGCGGCTTTGGTGACTCTAG \\
\hline & & RP: GGATTTAAAGTGGACTCATTCCAATT \\
\hline & & FAM: CGATGGTAGTCGCCGTGCCTACCA \\
\hline \multirow[t]{3}{*}{ 18SA } & 501 & FP: TTCGGAACTGAGGCCATGAT \\
\hline & & RP: CATGCCAGAGTCTCGTTCGTT \\
\hline & & FAM:CATTCGTATTGCGCCGCTAGAGGTG \\
\hline
\end{tabular}

Table 3. Real-time PCR Forward (FP) and Reverse (RP) Final Primer Concentrations for Human Pulp Samples

\begin{tabular}{|c|c|c|}
\hline $\begin{array}{c}\text { Primer } \\
\text { Combination }\end{array}$ & $\begin{array}{c}\text { Small Amplicon Primer Final } \\
\text { Concentration }(\mathbf{n M})\end{array}$ & $\begin{array}{c}\text { Large Amplicon Primer Final } \\
\text { Concentration (nM) }\end{array}$ \\
\hline \multirow[t]{2}{*}{$18 \mathrm{~S} 5 / 300$} & 18S5 FP: 50 & 18S300 FP: 500 \\
\hline & 18S5 RP: 100 & 18S300 RP: 500 \\
\hline \multirow[t]{2}{*}{$18 \mathrm{~S} \mathrm{~B} / 5$} & 18S5 FP: 900 & 18SB FP: 100 \\
\hline & 18S5 RP: 800 & 18SB RP: 100 \\
\hline \multirow[t]{2}{*}{$18 \mathrm{~S} \mathrm{~A} / \mathrm{B}^{*}$} & 18S B FP: 60 & 18SA FP: 1300 \\
\hline & 18S B RP: 60 & 18SA RP: 1300 \\
\hline \multirow[t]{2}{*}{$18 \mathrm{~S} 66 / 137$} & 18S66 FP: 1000 & 18S137 FP: 260 \\
\hline & 18S66 RP: 900 & 18S137 RP: 160 \\
\hline
\end{tabular}

*Note: This combination was previously optimized by Regina Trott and was hence applied to human samples. However, an attempt of optimization in this study was unsuccessful using the same noted parameters.

Colormetric analysis of tooth pulp

Once exposed, a portion of the pulp was photographed using a Leica S6D microscope and Leica DFC450 camera with Leica Application Suite 4.4 software (Grove Village, IL). 
Photographs of the pulp were analyzed the same way as the porcine samples, and again a kmeans cluster analysis was used to determine statistical similarities between samples with differing postmortem intervals.

qPCR data analysis

Cycle threshold values for each sample were obtained by setting qPCR baselines and thresholds according to Applied Biosystems' recommendations, which were kept constant for each run of the respective primer combination. Once all $\mathrm{Ct}$ values were obtained, the data was analyzed in the same matter as the porcine samples. 


\section{RESULTS}

\section{Porcine Samples}

Primer/probe multiplex optimization for qPCR

In order to apply the $2^{-\Delta \mathrm{Ct}}$ method of analysis for qPCR results [45], it is critical to ensure that all primer/probe sets in the multiplex reaction are working at relatively equal rates over a range of RNA concentrations. Hence, before applying a primer/probe combination to any pulp samples, the efficiency of each combination was optimized according to [45]. The efficiency of the primer/probe combination depends on the absolute value of the slope. The efficiency curve for the 18S 5/300 combination is shown in Figure 1.

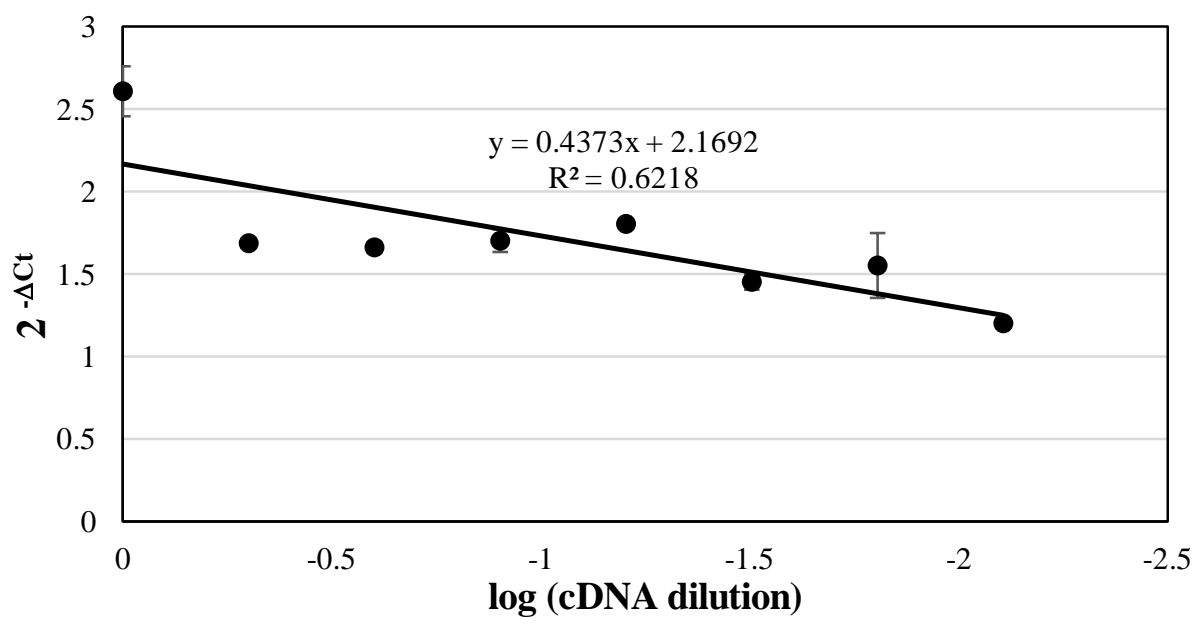

Figure 1. Efficiency of the $\mathbf{1 8 S} \mathbf{5 / 3 0 0}$ primer/probe combination for porcine RNA.

To determine the multiplexing efficiency of the pig 18S 5/300 primer and probe combination, a serial dilution of porcine cDNA was created from a $525 \mathrm{ng} / \mu \mathrm{L}$ stock sample. $18 \mathrm{~S} 5$ was $66 \mathrm{bp}$ while $18 \mathrm{~S} 300$ was $301 \mathrm{bp}$. PCR cycle threshold values were analyzed on a $2^{-\Delta \mathrm{CT}}$ scale, $(\Delta \mathrm{Ct}=$ $\left.\mathrm{Ct}_{300}-\mathrm{Ct}_{5}\right)$ and plotted against the log of serial cDNA dilutions. The multiplexing efficiency of the combination is determined by the absolute value of the slope $(n=16)$. Error bars represent standard error. 
Analysis of RNA degradation via qPCR

After isolation via organic extraction, the $18 \mathrm{~S}$ rRNA was converted to double stranded cDNA via reverse transcription. Once in the cDNA form, the samples were subjected to realtime PCR analysis (qPCR). Cycle threshold $(\mathrm{Ct})$ values were obtained from each sample for both the large (301 bp) and small (66 bp) amplicons. The $\mathrm{Ct}$ values were converted to a $2^{-\Delta \mathrm{Ct}}$ scale $\left(\Delta \mathrm{Ct}=\mathrm{Ct}_{301}-\mathrm{Ct}_{66}\right)$ to take into account that the values were actually on a logarithmic scale, due to the resulting exponential curve of the qPCR analysis [45] (Figure 2). Teeth were pulled and RNA was extracted from pigs from November 2013 to October 2014, across fall, winter, and summer seasons with the help of Joshua Moore. As time since death increased, the amount of total RNA decreased. Furthermore, as PMI increased, the larger amplicons degraded more rapidly than the smaller amplicons. As evident in Figure 2, there was a general downward trend in $2^{-\Delta \mathrm{Ct}}$ values as PMI increased, however, there were also unexpected increases around days 28,42 , and 70 . These incidences had no obvious explanation, but were seen repeatedly across multiple individual batches of pigs.

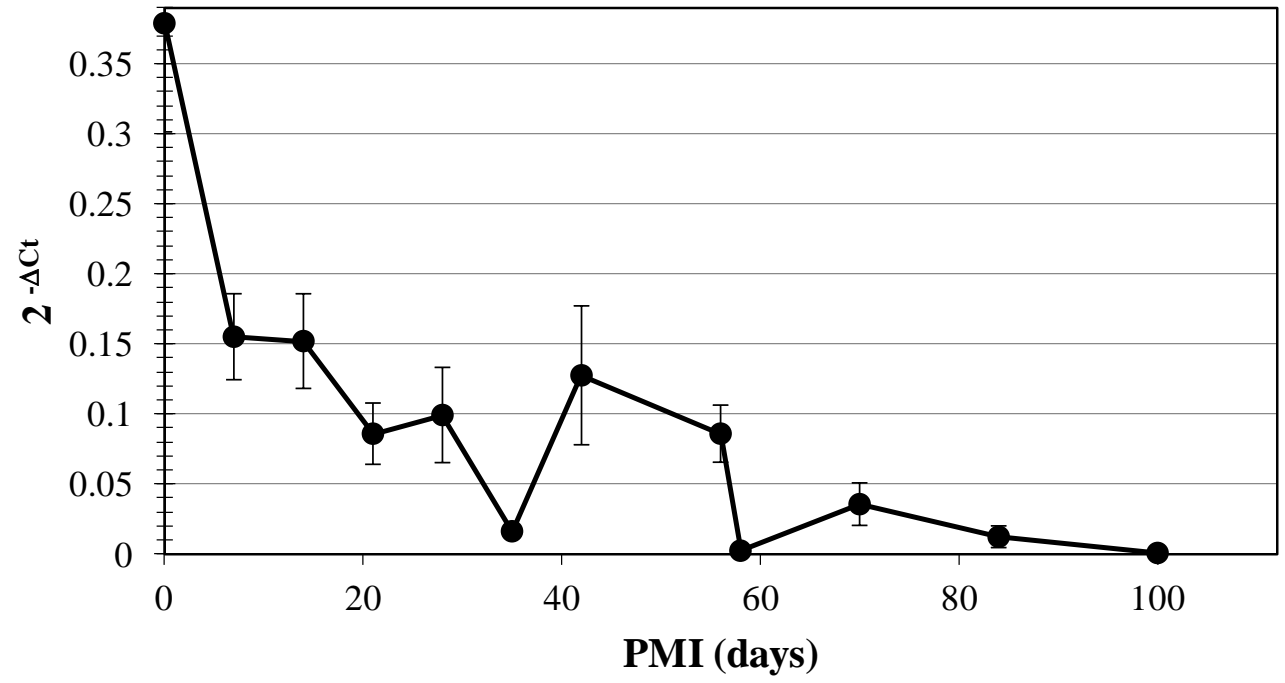

Figure 2. Real-time PCR analysis of porcine 18S rRNA degradation from dental pulp. Porcine tooth data, collected from July 2012 to September 2014 ( $n=376$ teeth), showing RNA degradation of a labile $301 \mathrm{bp}$ segment of $18 \mathrm{~S}$ rRNA compared to that of a more stable $66 \mathrm{bp}$ segment of the same $18 \mathrm{~S}$ rRNA molecule. PCR cycle threshold values were analyzed on a $2^{-\Delta \mathrm{CT}}$ scale, in accordance to the method proposed by Livak and Schmittigen (2001) $\left(\Delta \mathrm{Ct}=\mathrm{Ct}_{301}-\right.$ $\mathrm{Ct}_{66}$ ), while error bars represent standard error. As expected, there is a general downward trend 
of the $\mathrm{Ct}$ values as PMI increases. Sudden increases around days 28, 42, and 70 were unexpected but reproducible across multiple batches of pigs. These incidences may be due to a sudden increase in the degradation of the smaller rRNA segments compared to the degradation rate of the larger segments.

Colormetric and morphological analysis of pulp via microphotography and Adobe Photoshop

As shown in Table 4, pulp samples were able to be clustered into 3 distinct colors clusters. Cluster 1 contained samples from days 0-28, cluster 2 contained samples from days 3570 , and cluster 3 contained samples from days 100 and 126 post mortem. Cluster 1 had intermediate to high values for red but relatively low values for both blue and green. Cluster 2, on the other hand, had intermediate values for red and green, but low values for blue. Finally, cluster 3 had intermediate to high values for red, blue, and green. The mean and standard deviation for each cluster are given in Table 5. In general, as PMI increased the pulp underwent color and morphological changes. Soon after death, tooth pulp was more aqueous and bright red in color. However, as PMI increased, the pulp proceeded to become drier, turning into a more powder like substance and also became more white or grey in color at later PMIs.

Table 4. Color content of pig pulp images grouped into 3 clusters via K-means cluster analysis $(n=122$ teeth)

\begin{tabular}{|c|c|c|c|c|c|c|c|c|c|c|c|c|c|c|}
\cline { 2 - 13 } \multicolumn{1}{c|}{} & \multicolumn{10}{c|}{ PMI (Days) } \\
\hline Cluster: & $\mathbf{0}$ & $\mathbf{7}$ & $\mathbf{1 4}$ & $\mathbf{2 1}$ & $\mathbf{2 8}$ & $\mathbf{3 5}$ & $\mathbf{4 2}$ & $\mathbf{4 9}$ & $\mathbf{5 6}$ & $\mathbf{5 8}$ & $\mathbf{6 3}$ & $\mathbf{7 0}$ & $\mathbf{1 0 0}$ & $\mathbf{1 2 6}$ \\
\hline $\mathbf{1}$ & $\underline{19}$ & $\underline{18}$ & $\underline{10}$ & $\underline{10}$ & $\underline{7}$ & 0 & 0 & 0 & 0 & 1 & 0 & 0 & 0 & 0 \\
\hline $\mathbf{2}$ & 0 & 0 & 0 & 0 & 5 & $\underline{6}$ & $\underline{7}$ & $\underline{7}$ & $\underline{6}$ & $\underline{6}$ & $\underline{4}$ & $\underline{2}$ & 0 & 0 \\
\hline $\mathbf{3}$ & 0 & 0 & 0 & 0 & 0 & 0 & 0 & 0 & 0 & 0 & 0 & 0 & $\underline{7}$ & $\underline{7}$ \\
\hline Total: & 19 & 18 & 10 & 10 & 12 & 6 & 7 & 7 & 6 & 7 & 4 & 2 & 7 & 7 \\
\hline
\end{tabular}


Table 5. Mean and standard deviation values for color content in each K-means cluster

\begin{tabular}{ccccc}
\hline Cluster & & Red & Green & Blue \\
\hline 1 & Mean & 74.859 & -52.380 & -34.849 \\
& Standard Deviation & 53.130 & 59.253 & 57.896 \\
2 & Mean & 62.596 & 0.614 & -164.632 \\
& Standard Deviation & 53.674 & 54.700 & 60.242 \\
3 & Mean & 132.333 & 21.833 & 24.2 \\
& Standard Deviation & 35.648 & 43.063 & 50.455 \\
\hline
\end{tabular}

PMI estimation in ADD

Using the weather data obtained from a local weather station, approximately 1 mile from the collection site, accumulated degree days (ADD) were calculated for each extracted pulp sample. ADD takes into account the thermal factors that may affect RNA degradation, and is calculated by subtracting a designated lower threshold $\left(0^{\circ} \mathrm{C}\right)$ temperature from the mean daily temperature. All of the ADD values were then added up to assign each collection date a specific $\mathrm{ADD}$ value, considering the temperature changes that may have resulted in the $\mathrm{Ct}$ values obtained for that collection day. ADD calculations for fall, winter, and summer samples were then binned into increments of 25, 50, and 100 ADD (Figure 3). Overall, there was a general downward trend in the $2^{-\Delta \mathrm{Ct}}$ value as the ADD value increased.

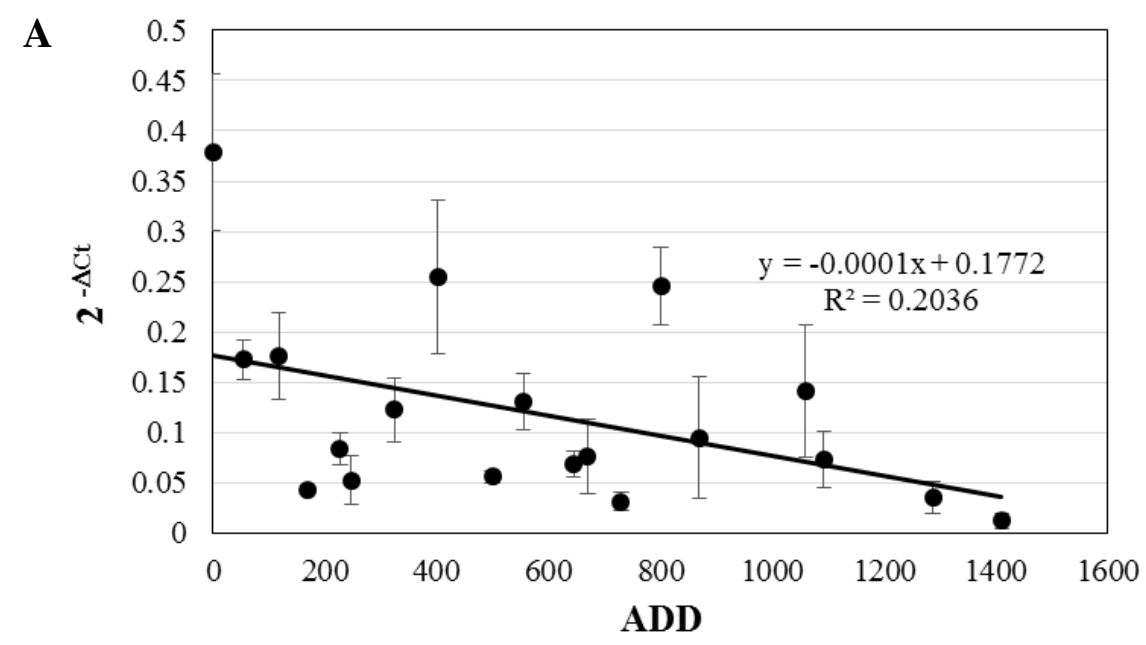



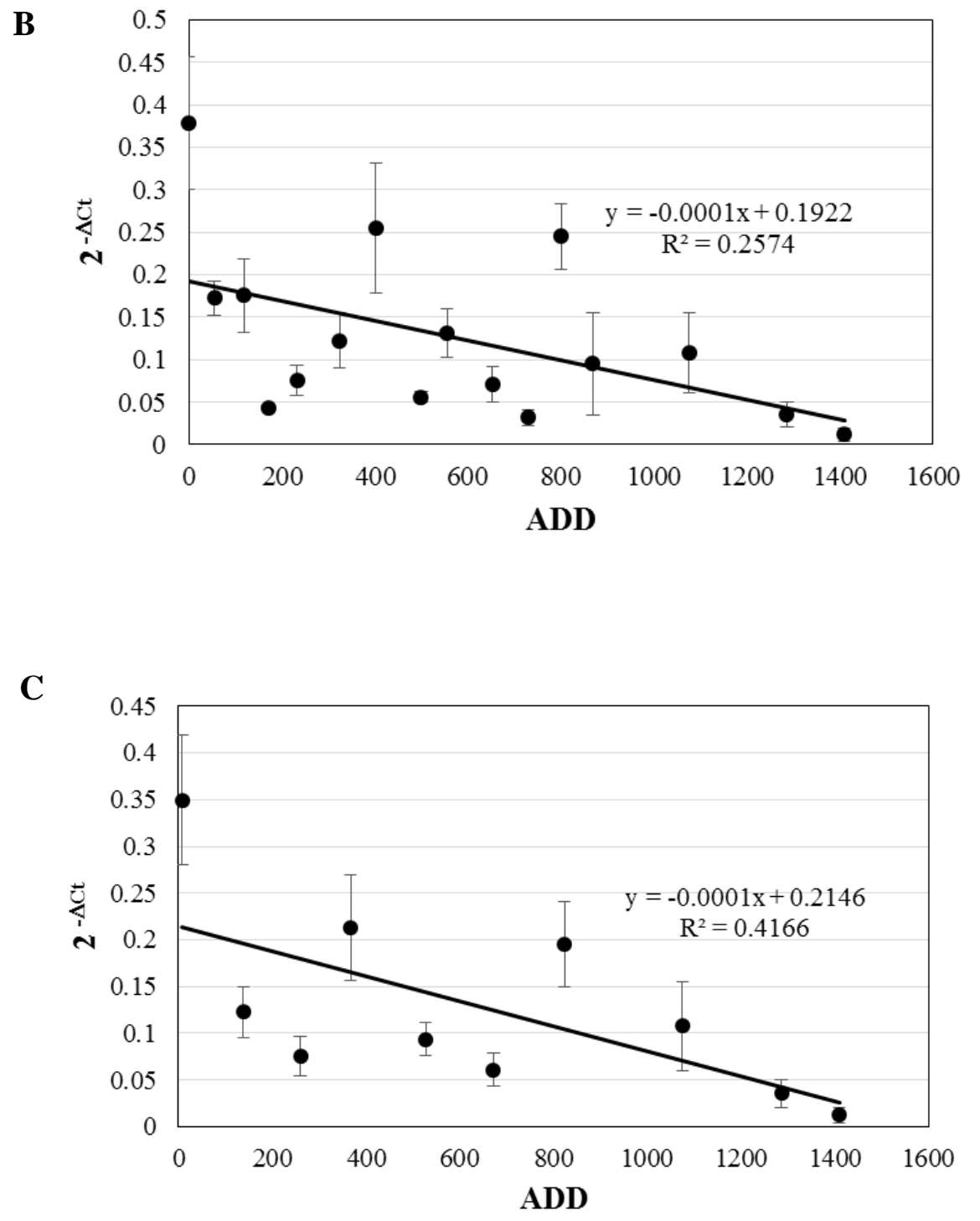

Figure 3. Real-time PCR analysis of porcine 18S rRNA degradation from dental pulp in accumulated degree days. The accumulated degree days (ADD) were calculated for each extracted sample, taking weather information into account. Samples were collected across summer, fall, and winter seasons ( $n=376$ teeth). The calculated ADD values from each sample were binned into 25 (A), 50 (B), and 100 (C) ADD increments. In each case, there was a general downward trend in $\mathrm{Ct}$ values as the $\mathrm{ADD}$ value increased. Error bars on each data point represent standard error. 
PMI estimation in calendar days vs. ADD

SAS JMP v. 11 was used to perform a multiple regression in order to determine whether a PMI estimate would be more accurate if estimated in calendar days or in ADD, considering all other factors involved: RNA degradation ( $2^{-\Delta \mathrm{Ct}}$ values) and red, blue, and green color content. Analysis of the fall data showed that a PMI estimate in ADD $\left(\mathrm{R}^{2}=0.95\right)$ was considered more accurate than calendar days $\left(\mathrm{R}^{2}=0.91\right)$. In the same way, winter data revealed ADD $\left(\mathrm{R}^{2}=0.94\right)$ was more accurate at estimating PMI than calendar days $\left(\mathrm{R}^{2}=0.91\right)$. Interestingly though, analysis of the summer data revealed that estimating PMI in either calendar days or in ADD was equally accurate, producing an $\mathrm{R}^{2}$ value of 0.65 for both estimations.

Another multiple regression was then performed on the more accurate PMI estimation method - ADD for fall and winter data, and calendar days and ADD for summer data - in order to formulate a predictive equation that included all known factors. A predictive equation would be useful for applying experimental values from qPCR and colormetric analyses in order to estimate a PMI (ADD or calendar days) for a given sample. An analysis of variance (ANOVA) was also conducted on the models to determine which factors significantly affected the PMI estimate. Figure 4 shows the multiple regression for each season, either in ADD or in calendar days, along with a corresponding ANOVA table. P-values were deemed significant if they were less than 0.05. As evident by Figure 4, PMI estimates from samples collected in the summer and fall were significantly impacted by RNA degradation as well as red, blue, and green color content values. Notably, however, PMI estimates for samples collected during winter months were only significantly impacted by green color content $(p=0.0007)$. Additionally, each of the graphs in Figure 4 displays a 95\% confidence interval in which the following equations can accurately estimate a PMI value (ADD or days):

Summer:

$$
\begin{aligned}
& \text { ADD }=\left(503.576-\left(417.536 * 2^{-\Delta C t}\right)-(1.915 * \text { Red })+(3.540 * \text { Green })-(1.388 * \text { Blue })\right) \pm 595.896 \\
& \text { Days }=\left(20.477-\left(16.999 * 2^{-\Delta C t}\right)-(0.0790 * \text { Red })+(0.145 * \text { Green })-(0.0588 * \text { Blue })\right) \pm 24.228
\end{aligned}
$$


Fall:

ADD $=\left(375.596-\left(381.841 * 2^{-\Delta C t}\right)-(3.420 *\right.$ Red $)+(6.856 *$ Green $)-(2.421 *$ Blue $\left.)\right) \pm 553.821$

Winter:

ADD $=(304.914-(853.133 * 2-\Delta \mathrm{Ct})-(0.147 *$ Red $)+(0.747 *$ Green $)-(0.387 *$ Blue $)) \pm 387.762$

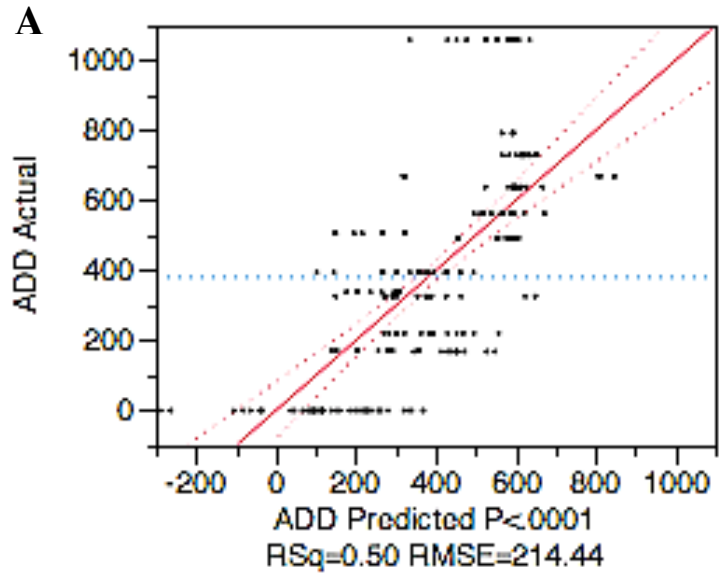

\begin{tabular}{|l|l|l|l|l|}
\hline $\begin{array}{l}\text { Source of } \\
\text { Variation }\end{array}$ & df & $\begin{array}{l}\text { Sum of } \\
\text { Squares }\end{array}$ & F & p \\
\hline $2^{-\Delta \mathrm{Ct}}$ & 1 & $2,058,642.8$ & 44.77 & $<0.0001$ \\
\hline Red color & 1 & $1,121,343.7$ & 24.39 & $<0.0001$ \\
\hline Blue color & 1 & $1,115,811.5$ & 24.27 & $<0.0001$ \\
\hline Green color & 1 & $5,949,950.5$ & 129.39 & $<0.0001$ \\
\hline Error & 236 & $10,852,199$ & \multicolumn{2}{|l}{} \\
\cline { 1 - 3 } & &
\end{tabular}




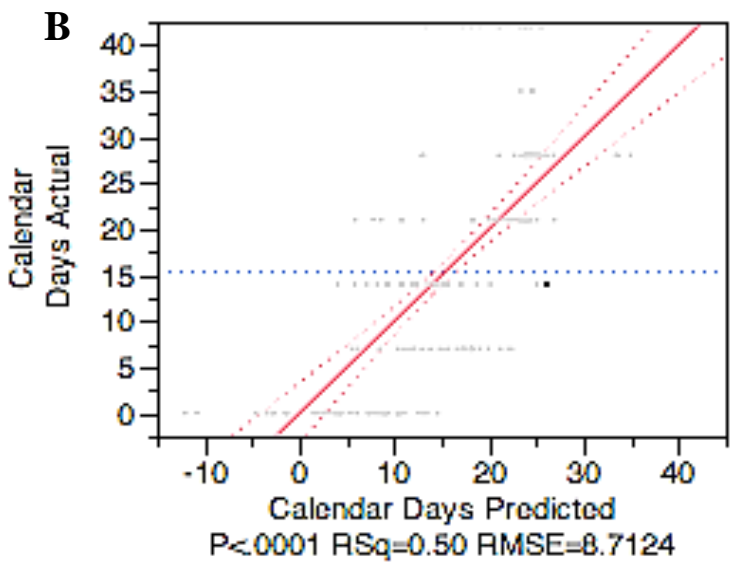

\begin{tabular}{|l|l|l|l|l|}
\hline $\begin{array}{l}\text { Source of } \\
\text { Variation }\end{array}$ & df & $\begin{array}{l}\text { Sum of } \\
\text { Squares }\end{array}$ & F & p \\
\hline $2^{-\Delta \mathrm{Ct}}$ & 1 & $3,412.27$ & 44.95 & $<0.0001$ \\
\hline Red color & 1 & $1,907.89$ & 25.14 & $<0.0001$ \\
\hline Blue color & 1 & $2,000.39$ & 26.35 & $<0.0001$ \\
\hline Green color & 1 & $10,024.49$ & 132.07 & $<0.0001$ \\
\hline Error & 236 & $17,913.64$ & & \multicolumn{1}{|l}{} \\
\cline { 1 - 3 } & &
\end{tabular}

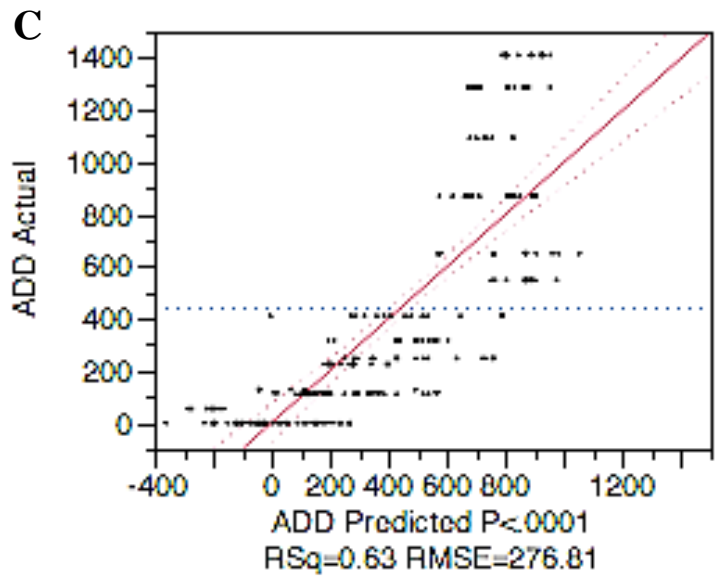

\begin{tabular}{|l|l|l|l|l|}
\hline $\begin{array}{l}\text { Source of } \\
\text { Variation }\end{array}$ & df & $\begin{array}{l}\text { Sum of } \\
\text { Squares }\end{array}$ & F & p \\
\hline $2^{-\Delta \mathrm{Ct}}$ & 1 & $1,320,897.2$ & 17.24 & $<0.0001$ \\
\hline Red color & 1 & $20,15252.1$ & 26.30 & $<0.0001$ \\
\hline Blue color & 1 & $482,849.7$ & 6.30 & 0.0127 \\
\hline Green color & 1 & $4,087,017.9$ & 53.34 & $<0.0001$ \\
\cline { 1 - 3 } Error & 257 & $19,691,909$ & \multicolumn{1}{|l}{} \\
\cline { 1 - 2 }
\end{tabular}




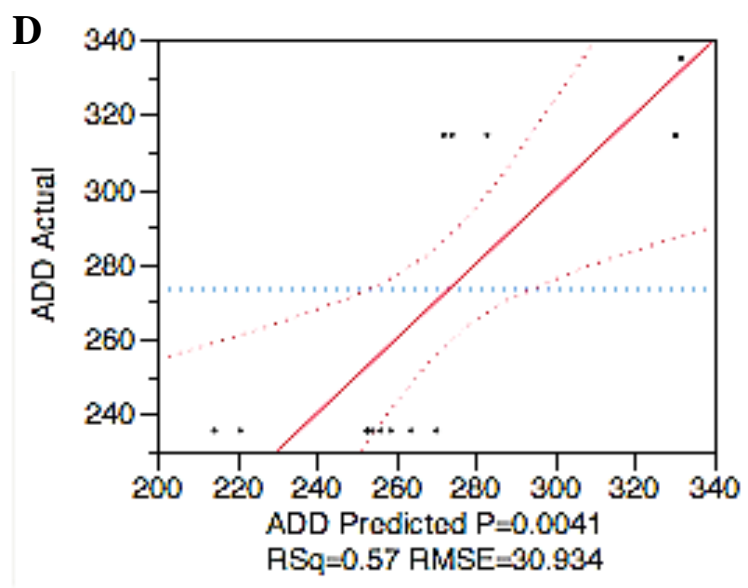

\begin{tabular}{|l|l|l|l|l|}
\hline $\begin{array}{l}\text { Source of } \\
\text { Variation }\end{array}$ & df & $\begin{array}{l}\text { Sum of } \\
\text { Squares }\end{array}$ & F & p \\
\hline $2^{-\Delta \mathrm{Ct}}$ & 1 & 62.28 & 0.0651 & 0.8017 \\
\hline Red color & 1 & 166.55 & 0.174 & 0.6818 \\
\hline Blue color & 1 & $2,344.34$ & 2.45 & 0.1360 \\
\hline Green color & 1 & $16,126.55$ & 16.85 & 0.0007 \\
\hline Error & 17 & $16,267.02$ & \multicolumn{2}{|l}{} \\
\cline { 1 - 3 } & \multicolumn{3}{|l|}{} &
\end{tabular}

\section{Figure 4. Production of a predictive equation to estimate PMI.}

A multiple regression was constructed in JMP to formulate a predictive equation for estimating PMI in ADD. The analysis takes into account the color content and real-time RT-PCR Ct values for summer (A, B) ( $n=152$ teeth), fall (C) ( $n=186$ teeth), and winter (D) ( $n=38$ teeth) models. A prior multiple regression for the summer data set revealed that both ADD (A) and calendar days $(B)$ have the same predictive power $\left(R^{2}=0.65\right)$, and hence, a predictive equation for PMI was constructed in both ADD and calendar days. The blue line in each graph represents the mean actual ADD value for the data set. The solid red line indicates where the predicted ADD and the actual ADD values are equal, while the dotted red lines represent $95 \%$ confidence limits. An associated ANOVA table is listed with each predictive model, indicating significant factors with p-values that are less than 0.05 . 


\section{Human Samples}

Primer/probe multiplex optimization for $q P C R$

When using the $2^{-\Delta \mathrm{Ct}}$ method of analysis for qPCR results [45], all primer/probe sets in the multiplex reaction must be working at relatively equal rates. Hence, before applying a primer/probe combination to any pulp samples, the efficiency of each combination was optimized according to [45]. The efficiency of the primer/probe combination depends on the absolute value of the slope. The efficiency curve for the human $18 \mathrm{~S} 5 / 300,18 \mathrm{~S} \mathrm{~B} / 5$, and $18 \mathrm{~S}$ 66/137 combinations are shown in Figure 5. Combination 18S A/B was noted to be previously optimized by Regina Trott, but proper efficiency could not be repeated in this study under identical conditions and concentrations. 
A.) $18 \mathrm{~S} 5 / 300$

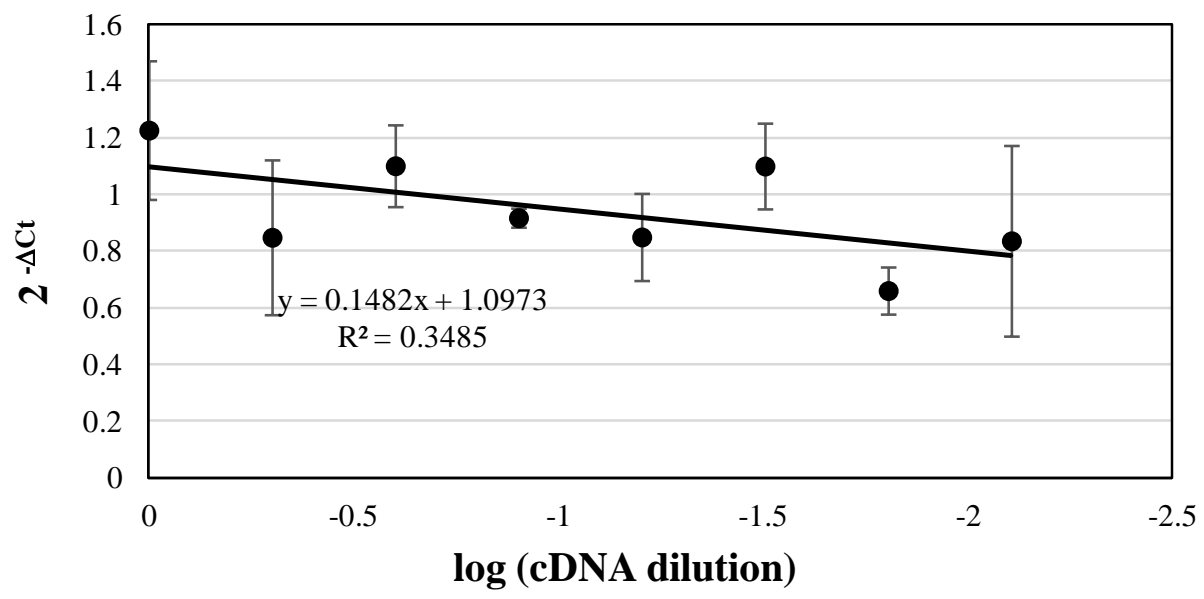

B.) $18 \mathrm{~S} \mathrm{~B} / \mathbf{5}$

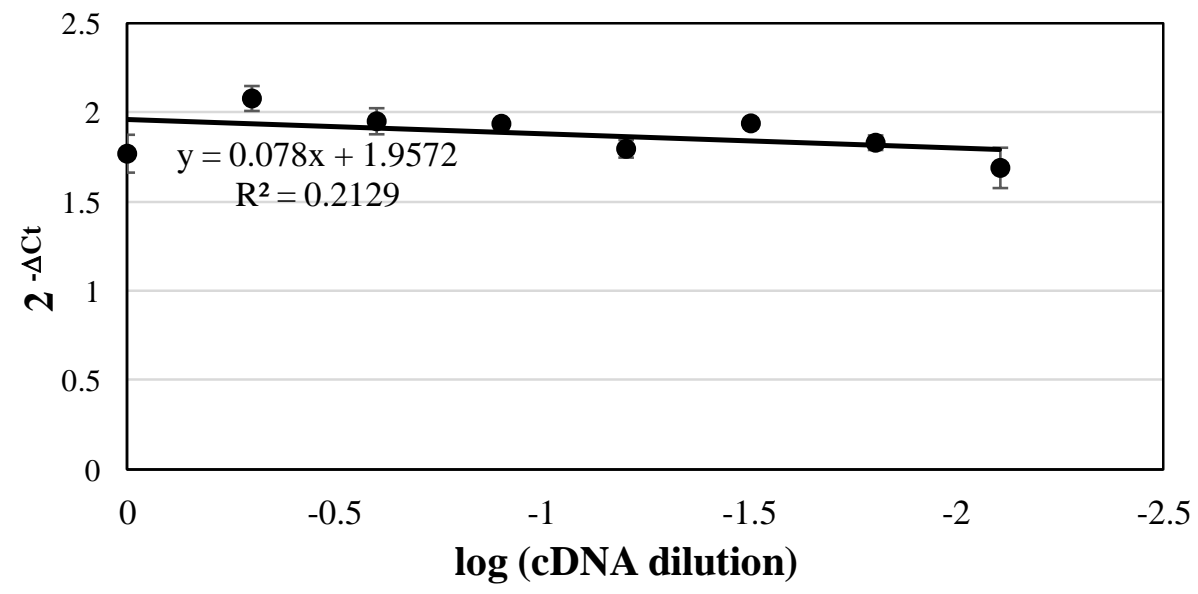

\section{C.) $18 \mathrm{~S} 66 / 137$}

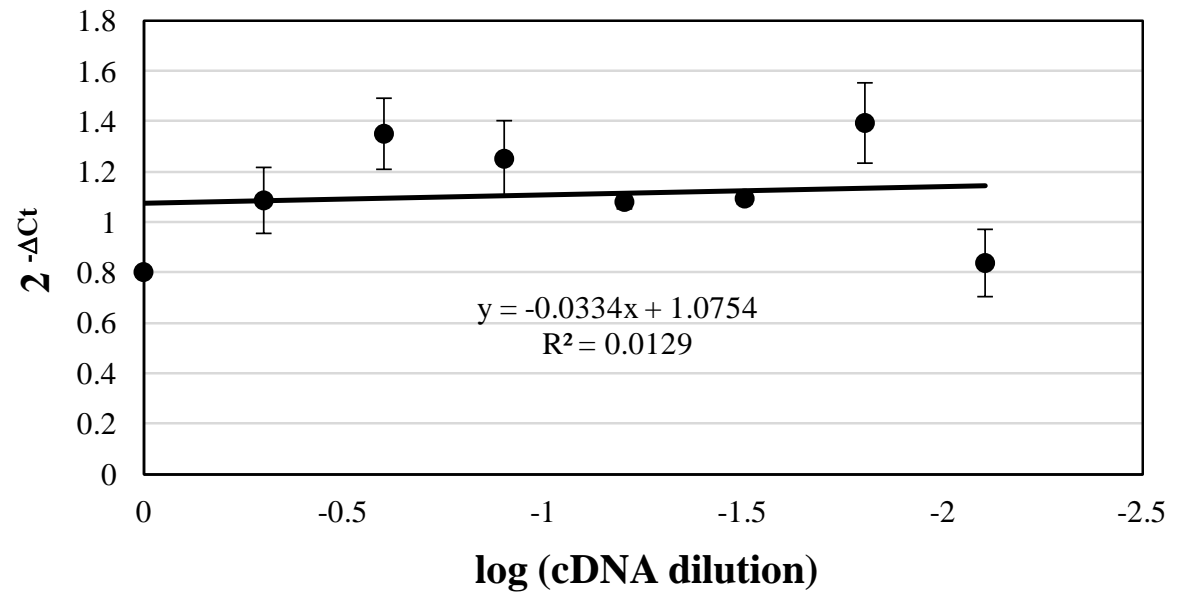


Figure 5. Efficiency of the $18 \mathrm{~S} 5 / 300,18 \mathrm{~S} \mathrm{B/5}$, and $18 \mathrm{~S} 66 / 137$ primer/probe combination for human RNA. To determine the multiplexing efficiency of the human $18 \mathrm{~S} 5 / 300$ (A), 18S B/5 (B), and 18S 66/137 (C) primer and probe combinations, a serial dilution was performed on cDNA extracted and converted from a human blood sample. 18S 5 was 66 bp while 18S 300 was 301 bp; 18S B was 171 bp while $18 \mathrm{~S} 5$ was 66 bp; and 18S 66 was 66 bp while $18 \mathrm{~S} 137$ was $137 \mathrm{bp}$. PCR cycle threshold values were analyzed on a $2^{-\Delta \mathrm{CT}}$ scale, $(\Delta \mathrm{Ct}=$ $\mathrm{Ct}_{\text {large amplicon }}-\mathrm{Ct}_{\text {small amplicon }}$ ) and plotted against the log of serial cDNA dilutions. The multiplexing efficiency of the combination is determined by the absolute value of the slope $(\mathrm{n}=16$ each graph). Error bars on each graph represent standard error.

\section{Analysis of RNA degradation via $q P C R$}

Teeth were pulled and RNA was extracted from 16 human specimens from May 2013 to November 2014, across all seasons. Specimens (male and female) used in the study ranged from ages 18 - 95, with 15 of 16 specimens being above the age of 50. In addition, it was noted that most of specimens had a great deal of dental work or were missing teeth. The cause of death for the specimens were either natural causes or health complications that were not known to affect the oral cavity. After isolation via organic extraction, the $18 \mathrm{~S}$ rRNA was converted to double stranded cDNA via reverse transcription and real-time PCR analysis (qPCR) was performed. Unfortunately, no general trend seemed to be evident among the human specimens for any of the primer/probe combinations applied. However, it was noted that $18 \mathrm{~S} \mathrm{~B} / 5$ analysis of the pulp from the 18 year old specimen showed a general, though still sporadic, trend with decreasing $2^{-}$ ${ }^{\Delta \mathrm{Ct}}$ values with increasing PMI. A comparison of $18 \mathrm{~S}$ B/5 analysis for the 18 year old specimen and a 95 year old specimen (the oldest specimen analyzed) is shown in Figure 6. With the exception of the 18 year old, most of the trends observed were similar to that of the 95 year old

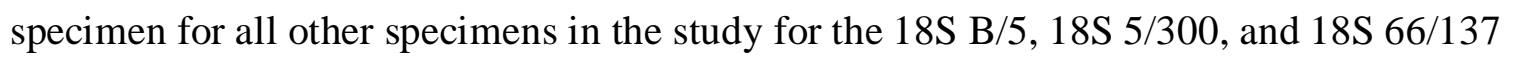
combinations (data not shown). Hence, the qPCR analysis of tooth pulp from human samples was overall inconclusive. 

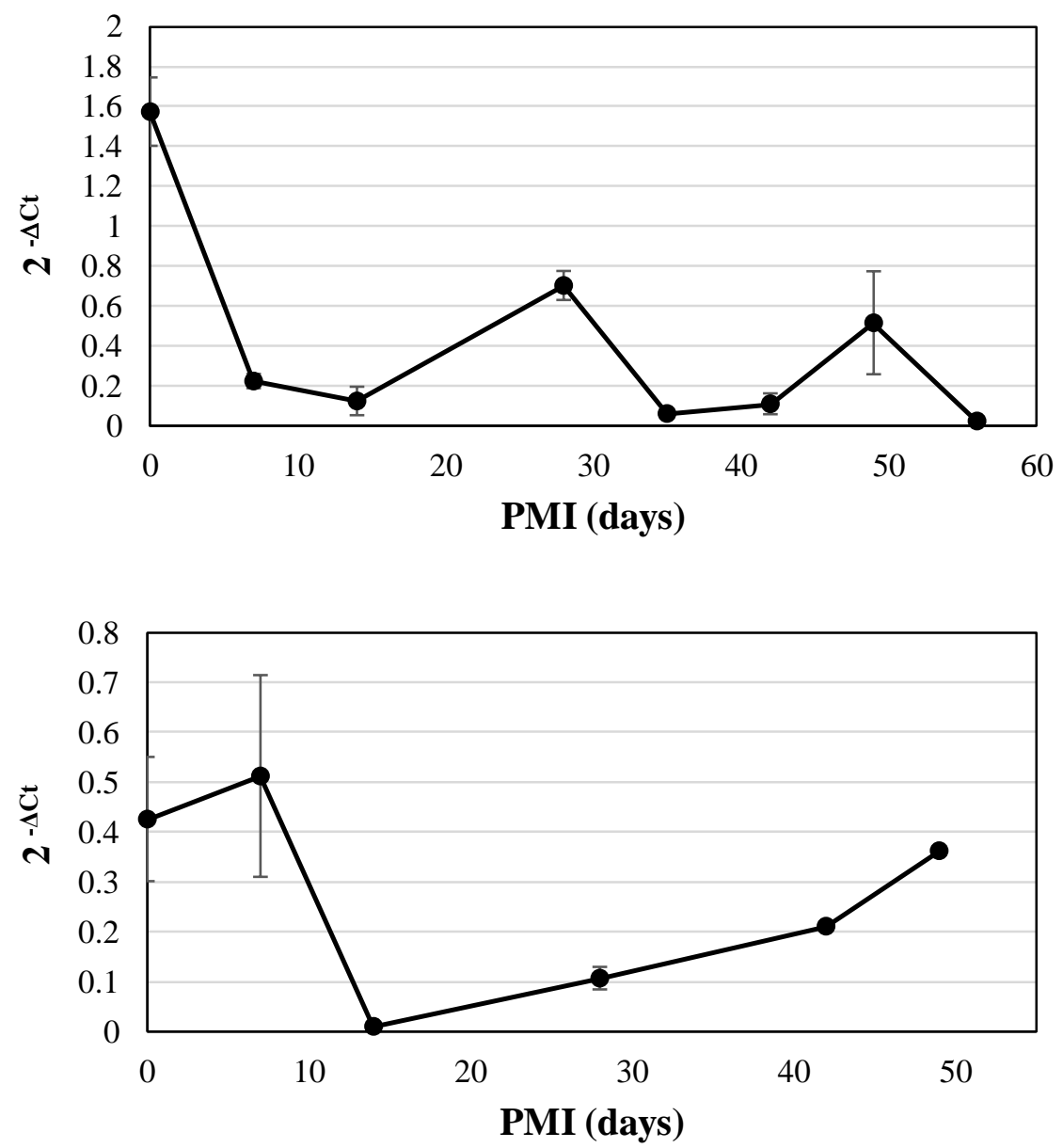

Figure 6. Real-time PCR analysis of human 18S rRNA degradation from dental pulp. Human tooth data, collected from September to November 2014, showing RNA degradation of a labile $171 \mathrm{bp}$ segment of $18 \mathrm{~S}$ rRNA compared to that of a more stable $66 \mathrm{bp}$ segment of the same $18 \mathrm{~S}$ rRNA molecule. PCR cycle threshold values were analyzed on a $2^{-\Delta \mathrm{CT}}$ scale, in accordance to the method proposed by Livak and Schmittigen [45] $\left(\Delta \mathrm{Ct}=\mathrm{Ct}_{171}-\mathrm{Ct}_{66}\right)$, while error bars represent standard error. The graph on the top is data collected from an 18 year old specimen ( $\mathrm{n}=16$ teeth), while the graph on the bottom is data collected from a 95 year old specimen ( $n=12$ teeth). It is important to note that the graph of the 18 year old sample has more valid data points and potentially a more extended PMI estimation than the graph of the 95 year old. 
Colormetric and morphological analysis of pulp via microphotography and Adobe Photoshop

Once the pulp was exposed, a small portion was photographed with a Leica S6D microscope and Leica DFC450 camera. Unfortunately, clustering of samples based on PMI and color content was unsuccessful. Early PMI samples seemed to have similar color content as later PMI samples, clustering them together rather than clustering samples around the same PMI (data not shown). Hence, color content was not a useful indication of a PMI estimate.

It is, however, important to note that the color and morphology of pulp seemed to be variable among all human specimens. Most importantly, it was observed that pulp from the 18 year old specimen was morphologically different than most other samples. Soon after death, the pulp was bright red and aqueous, fading in color while still being somewhat aqueous and eventually becoming powder like at late PMIs. However, older specimen samples tended to be a darker red or white soon after death. In addition, not all pulp samples were aqueous immediately after death in the older specimens. Some pulp samples were more string-like and eventually changed into a powder-like substance as PMI increased. 


\section{DISCUSSION}

\section{Porcine Samples}

The project presented here worked to create an independent, objective biological method to estimate PMI by analyzing the degradation of $18 \mathrm{~S}$ rRNA from dental pulp. Using reverse transcription real-time PCR, the amount of RNA present in dental pulp samples at different PMIs was measured. Data revealed that $18 \mathrm{~S}$ rRNA was present in porcine tooth pulp up to 100 days postmortem (Figure 2). Further, since the total amount of RNA present in a tissue depends on the tissue type as well as the individual's health and age, this study employed a quantification method analogous to radioactive carbon dating. By monitoring the extent of degradation of a large, labile and small, stable segment from the same $18 \mathrm{~S}$ rRNA molecule, a PMI for the specimens could be estimated. Since the larger segments of RNA create a larger target for degradation forces, it was expected and observed that the larger segments would degrade at a faster rate than the smaller segments. The relationship of the degradation rates of the large (301 bp) and small (71 bp) segments was analyzed using the $2^{-\Delta \mathrm{Ct}}$ method $\left(\Delta \mathrm{Ct}=\mathrm{Ct}_{301}\right.$ $-\mathrm{Ct}_{71}$ ) [45]. As PMI increased, the $2^{-\Delta \mathrm{Ct}}$ value generally decreased (Figure 2).

Though the overall relationship between increasing PMI and decreasing total RNA (measured as Ct values) was not exactly linear, there was an obvious decreasing trend in the total amount of $18 \mathrm{~S}$ rRNA present in porcine dental pulp as the amount of time since death

increased. Interestingly, there were sudden increases in $2^{-\Delta \mathrm{Ct}}$ values at days 28,42 , and 70 postmortem. Though the exact reason for these incidences is unknown, this same pattern was observed in multiple individual data sets and studies [43]. Raw PCR data (not shown) indicated a sudden increase in the degradation of the smaller (71 bp) segment at these times. This may be due to a sudden change in the enzyme or chemical composition being produced by the decomposing body at these times. Unfortunately, these incidences may also create a problem for estimating a PMI using the same primers and amplicons as used in this study. Future studies could use smaller amplicons in order to get a better estimate of $18 \mathrm{~S}$ rRNA degradation at these time points. 
In addition to the degradation of RNA, the dental pulp exhibited morphological changes as PMI increased. Though this project was not the first to observe these types of morphological changes [42], it did employ a quantitative method to objectively measure the changes. Adobe Photoshop was used to quantify the red, blue, and green color content of the photographed pulp samples. Generally, the pulp color changed from a bright red color when relatively fresh, to a darker, greyer color as PMI increased (Table 4). Additionally, as PMI increased, the pulp texture changed from an aqueous material to a dried out powder-like material. Employing a method such as this can potentially help determine what type of primers (i.e. size of PCR amplicon targets) to use for PCR analysis. For example, if a pulp sample is collected from a specimen and it is light in color - i.e. intermediate red, blue, and green intensity values - the analyst may have to use a set of primers that produce smaller PCR amplicons in order to accurately measure the amount of RNA present so a more reliable PMI estimate could be made. Unfortunately, when subjected to a k-means cluster analysis (Table 4), not all samples with the same PMI were placed in the same color cluster every time. Hence, it is important to note that based on the data obtained in this study, the colormetric analysis should not be used alone to estimate a PMI, but it can increase the reliability of the PMI estimate when combined with $18 \mathrm{~S}$ rRNA degradation analysis.

Temperature is known to have an important effect on the stability and degradation of DNA and RNA $[48,49]$. Hence, in an attempt to provide a more reliable PMI estimate that could be applied across seasons, accumulated degree days (ADD) were calculated for the samples studied. ADD measures the amount of thermal units applied to a system and is commonly used in agricultural and entomological studies. After statistical analysis, it was observed that a PMI estimate made in ADD was more reliable than when only considering calendar days for the fall and winter samples. Interestingly, for the summer samples, both calendar days and ADD exhibited the same predictive power, allowing a PMI to be estimated in both units. Further studies would have to be done on summer samples, but if PMI can be accurately estimated using only calendar days, then an additional calculation for ADD would not be necessary. 
In order to extend and predict a PMI estimate beyond the collected data, a predictive ADD (fall, winter, and summer) or calendar days (summer) equation was formed, considering all measured variables: $2^{-\Delta \mathrm{Ct}}$, red content, blue content, and green content (Figure 4). Interestingly, associated ANOVAs for each model reveal that all four values significantly affect a PMI estimate in summer and fall samples, but only the green color content significantly affects a PMI estimate for samples collected in the winter (Figure 4). Models produced by Young showed a similar influence of only the green color content for summer and winter studies [44]. Though more studies would have to confirm these results, this model can easily be incorporated into a forensic investigation if the time since death for the victim is unknown.

Though this method was relatively successful with porcine samples, there were a few notes about the specimens to consider for future studies. In this study, all pig heads were obtained from a local butcher shop and were assumed to be butchered within several hours of retrieval. This was done in order to keep the time of death for each specimen consistent, and as minimal as possible for a Day 0 extraction for each batch of specimens. However, this was not always under the researcher's control. Furthermore, since the specimens were obtained from a butcher shop, the ages of the pigs were not known. It was assumed that since the pigs were being used for food that they were in generally good health, though, so no diseases or other health conditions of the animals were taken into consideration. In addition, teeth that looked to be physically damaged were not included in the study. Still, it is important to note that these are factors that could potentially affect the condition, stability, and amount of the 18S rRNA present $[39,40]$. Moreover, as expected, it was observed that the type of tooth that was collected had an effect on the amount of pulp present for extraction. Molars often exhibited the largest amount of pulp, while incisors and some front premolars presented much less, and canines had very little to none. Even though a ratio of large and small $18 \mathrm{~S}$ rRNA segments is applied for measurement, the amount of pulp may affect the extraction procedure. If too little pulp is present, even slight error in the extraction procedure or RNA purification could result in a false negative or a falsely decreased quantification result from the real-time RT-PCR analysis. This is important to take into consideration when applying to a forensic case. If a full dental sample is available for a victim, it may be more beneficial to take a dental pulp sample from a molar or premolar, rather than an incisor, in order to best predict when the victim had died. 


\section{Human Samples}

With the successful analysis of porcine samples, the presented method was applied to human specimens in order to create an independent, objective biological method to estimate PMI for forensic investigations. Human specimens were obtained through the West Virginia University Human Gift Registry and ranged from ages 18 to 95, with 15 of the 16 specimens being above the age of 50. The time of death was approximately 24-72 hours prior to specimen retrieval. Using reverse transcription real-time PCR, the amount of $18 \mathrm{~S}$ rRNA present in dental pulp samples at different PMIs was measured. Unfortunately, no significant trend was seen on any individual or combined data set (data not shown) of various primer combinations. The same 18S 5/300 primer combination (66 bp and $301 \mathrm{bp}$ ) that was successful with porcine samples did not produce the same success on human samples. Though the genomic sequences are the same for both organisms, it can be hypothesized that this region is more variable in humans than it is in pigs; however, this was not examined.

In attempt to obtain successful and reliable real-time RT-PCR data, new primer/probe combinations were created, shortening both the large and small segment targets in hopes that the smaller segments would still be intact for an extended period of time. As previously mentioned, before applying the combinations to samples, the primer/probe combinations must first be optimized in a multiplex reaction using a serial dilution of cDNA [45]. After multiple attempts, an 18S rRNA combination targeting 66 and 193 bp segments, a 12S mitochondrial rRNA combination targeting 91 and 246 bp segments, and a 16S rRNA combination targeting 63 and 150 bp segments were unable to be properly optimized. The 18S A/B combination (Table 3) was previously optimized by another researcher in the lab and was hence applied to human samples. However, data obtained using this combination was unsuccessful, and when optimization was attempted again in this study, successful optimization of the primer/probe combination could not be achieved. Importantly, an 18S rRNA combination targeting 66 and 301 bp segments, 66 and 171 bp segments, and 66 and 137 bp segments, respectively (Table 3), were successfully optimized but unsuccessful at obtaining PMI estimation data from the studied specimens. 
In addition to RNA degradation analysis, the morphological characteristics of each dental pulp sample were photographed and noted. The red, blue, and green color content of each pulp photograph was objectively quantified using Adobe Photoshop. Due to the high degree of variation among specimen samples, a k-means cluster statistical analysis was unable to group samples based on PMI and color content (data not shown). However, the degree of variation between specimen samples itself is noteworthy. The initial color and texture of the dental pulp varied between individual specimens. Some of the younger aged specimens exhibited a relatively bright red pulp sample that was more aqueous in texture, while some of the older specimens exhibited a pink or even white pulp sample that was stringier and less aqueous in texture. Moreover, as PMI increased, the individual pulp samples exhibited different morphological changes, depending on their initial morphological state. Some of the specimens from older donors dental pulp samples were in a dehydrated, powder form even at early PMIs. For instance, the 95 year old specimen pulp sample was in a white powder form at 14 days postmortem. With such variability, the use of morphological and color changes in dental pulp to estimate a PMI or to determine what primer combination to use would be difficult.

Though the proposed method was generally unsuccessful for the human specimens studied here, it should not be discounted as a method to estimate PMI in forensic investigations. Even though the colormetric and RNA degradation analyses did not result in any obvious trends, it is important to highlight the 18 year old specimen. This was the youngest specimen obtained for the study from the WVU Human Gift Registry by at least 37 years. Though the age, condition, and gender of the specimens were beyond the researcher's control, the method was applied to any samples that were given. Hence, as evident in Figure 6, it could be speculated that age is an important factor that may have influenced the outcome of this study. When analyzing the 18 year old specimen samples via real-time RT-PCR, a general decrease in the amount of $18 \mathrm{~S}$ rRNA was observed as PMI increased (Figure 6). This trend is actually quite similar to the trend seen in the porcine sample study, though it only measured RNA degradation up to 56 days postmortem. The unexpected increases around days 28 and 49 are also similar to those found in repeated porcine sample studies (Figure 2). Though the exact reason for these incidences is unknown, this occurrence may again be due to a sudden change in the enzyme or chemical composition being produced by the decomposing body at these times. Yet, this 
hypothesis is not as supported as it is with the porcine samples since this exact trend was only seen in one human specimen.

Irrespective of increased PMI, the total amount of RNA present (especially at Day 0 postmortem) between samples of the different ages was evident. Touchberry et al. also observed a difference in the amount of housekeeping RNA, specifically $\beta 2$-microglobulin $(\beta 2 \mathrm{M})$, when measuring mRNA levels in human muscle tissue from two different age groups: younger (mean age $22.7 \pm 3.4 \mathrm{yrs}$ ) and older (mean age $73.0 \pm 9.5 \mathrm{yrs}$ ) [40]. Additionally, Uddin et al. found differing housekeeping gene expression levels depending on tissue and age when measuring RNA levels from porcine peripheral blood, lymph nodes, intestinal mucosa, stomach, liver, spleen, thymus, lung, kidney, heart and skin in 1 day, 2 month, and 5 month old pigs [39]. Therefore, in order to increase the reliability and accuracy of the proposed PMI estimation method, further studies need to be conducted on younger human specimens. With the expectation that younger specimens have more RNA present in dental pulp, a more precise PMI estimate may be able to be made when measuring 18S, 12S, or 16S RNA degradation.

Not only does the amount of RNA decrease as age increases, so does the amount of dental pulp present per tooth. In this study, it was noted that the younger human specimens generally had more pulp present in tooth samples than the older specimens, which could hinder the extraction process and eventually PCR and data analysis by giving false negative or falsely decreased quantification results. It has been shown that the size of the pulp sample, as well as the pulp chamber actually decrease with increasing age [50]. Atsu et al. (2005) noted that the physiological secondary dentin height increases with chronological age, making the space where the dental pulp resides smaller [50]. Additionally, the thickness of the tooth enamel surrounding the pulp was seen to begin decreasing for patients over the age of 50 [50]. Since the majority of the human specimens received for this study were above the age of 50, this loss is likely to have affected the outcome of the method; the smaller the pulp sample, the smaller amount of total RNA present. In similar regards, it was noted that many specimens had a great deal of dental work and/or missing teeth which also decreased the amount of samples that could be examined. As expected, if a victim had a root canal, the tooth was still available but a pulp sample was not. On the other hand, if the victim had an amalgam or composite resin filling or a 
dental crown in place, the tooth was still available but the amount of pulp may or may not have decreased, depending on the amount of dental decay prior to the procedure.

Finally, it is important to emphasize that the morphological condition of the 18 year old human specimen dental pulp sample was similar to the porcine specimen samples: exhibited a red, aqueous pulp sample at early PMIs and became darker and more dehydrated as PMI increased. On the other hand, older specimen samples were much more variable, some becoming dehydrated and powder-like at earlier PMIs. In living human specimens, it was found that the number of blood vessels present in teeth decreased as age increased, resulting in a significant decline in resting pulpal blood flow with increasing age [51]. Calcification of related tissues and nerves also increased with age, which in turn decreased the amount of pulp present in older patients [51]. Hence, with impeded blood flow in older victims, the color and morphology of the pulp sample may differ from younger victims. Unfortunately, this may introduce problems when attempting to determine which primer/probe combination should be used depending on the level of morphological change or decomposition. This further signifies that this method of PMI estimation may be more reliable on younger human specimens, though it was not further examined here. 


\section{FINAL CONCLUSIONS}

Postmortem interval (PMI), or time since death, is a critical component that is used to rebuild a series of events at a particular crime scene for forensic investigations. Several methods are currently used to estimate a PMI, including physiological, biochemical, entomological, and archeological approaches. However, most of these methods are subjective and are not effective in estimating PMIs extending from several weeks to months. This study aimed to use RNA degradation rates of housekeeping genes and quantitative color measurements of dental pulp to estimate a PMI after an extended period of decay. RNA was chosen for analysis due to its great abundance and relatively quick degradation process when compared to DNA, which takes several years to fully degrade without any external interference such as UV light or heat. Housekeeping genes, in particular, are expressed in relatively high quantities in all cell types since they are needed for the regulation of basic cellular function and growth processes. Moreover, dental pulp is an excellent source for this genetic material because it is physically protected by the tooth enamel and bone of the jaw, which does not decompose as quickly as some of the other body tissues. Teeth were also selected because each tooth presents an individual sample of pulp without exposing or harming any surrounding pulp sample. Though it was not investigated, bone marrow from hand bones may also create the same effect and could be examined in future studies.

After previous success of this method by Young, et al. (2013) via analysis of $\beta$-actin mRNA in porcine dental pulp [43,44], this study analyzed $18 \mathrm{~S}$ rRNA degradation in both porcine and human dental pulp samples. Decreasing amounts 18S rRNA were measured, via real-time RT-PCR, in porcine samples out to 100 days postmortem (Figure 2), but only in one, 18 year old human specimen out to 56 days postmortem (Figure 6). Additionally, using Adobe Photoshop, similarities in red, blue, and green color content of the pulp were observed for porcine samples, allowing them to be grouped into 3 clusters, depending on color content and PMI (Table 4). However, due to high variability in the human specimens, pulp samples were unable to be clustered in the same way (data not shown). Since temperature has a strong influence on the rate of RNA degradation [17, 48, 49], accumulated degree days (ADD) were also used to estimate PMI for porcine samples. Statistical analysis revealed that this method 
may be more accurate than estimating a PMI in calendar days. Even further, using the known variables $\left(2^{-\Delta \mathrm{Ct}}\right.$, red content, blue content, and green content), a predictive equation was produced in order to estimate a PMI in either calendar days or ADD for summer, fall, and winter porcine samples. The application of such an equation could be extremely beneficial to a forensic investigation when the time since death of the victim is unknown and minimal evidence or background information about the incident is provided.

Data collected from Young et al. (2013) porcine samples, the porcine samples herein, and the 18-year old human samples, provide evidence that this may be an extremely beneficial method to estimate a PMI, though further studies should confirm. It is evident that age has a robust impact on RNA degradation rates as well as dental conditions. Not only does the amount of RNA present decrease with age, but the amount of blood flow to each tooth, the pulp chamber, and the total amount of pulp per tooth also decline with age [50, 51]. The human specimens received for this study were donated to science and were therefore older people. Even though it was beyond the control of the researchers for this study, future studies should analyze RNA degradation patterns of dental pulp in younger human specimens. This study provides optimized [45] real-time RT-PCR primer/probe combinations that may be useful for such specimens (Table 3), but were only tested on one 18-year old specimen due to resource constraints.

It may also be beneficial to consider microRNA degradation analysis for extended PMI estimates. Due to their small size, approximately 21-25 bp, microRNAs are expected to degrade at a slower rate and could possibly act as the smaller segment in the large to small $2^{-\Delta \mathrm{Ct}}\left(\Delta \mathrm{Ct}_{\text {large }}\right.$ $\left.-\Delta \mathrm{Ct}_{\text {small }}\right)$ measurement of degradation presented herein. It has been found that, though the $18 \mathrm{~S}$ rRNA transcript is stable and reliable for estimating a PMI up to $336 \mathrm{~h}$ postmortem, microRNAs are even more stable, as they are less affected by temperature [52]. In the presented study, most of the smaller segments of the $18 \mathrm{~S}$ rRNA analyzed were still present in the dental pulp sample at later PMIs, with the larger segments of the molecule becoming completely degraded. Hence, using similar "small” segment sizes and sequences along with microRNAs, may allow for a PMI estimate to be made beyond the 100 days observed here. 
Another possible method of measurement of extensive RNA degradation that could be explored is the use of digital PCR, which has become more industrialized in recent years. Rather than amplifying a collection of PCR targets to quantify it, this method directly counts individual PCR target molecules down to a single molecule [53]. When comparing digital PCR to real-time RT-PCR techniques, digital PCR results were much more sensitive, precise, and reproducible, allowing for extensive microRNA analysis [54]. This method may be extremely critical for the presented method, especially with earlier PMIs when the larger RNA target segments begin to degrade rapidly, or with later PMIs when both, the large and the small segments, have become extensively degraded. This precise method of quantification may allow for more accurate PMI estimates.

In this study, RNA was isolated from porcine and human dental pulp in order to monitor its degradation rate so that it can be used as an objective method of estimating postmortem. Determining a PMI is crucial to forensic investigations when reconstructing how a crime occurred, especially when limited evidence or witnesses are available. This estimation of PMI has the potential to fill the time gap between the times where entomology is no longer an appropriate estimate, but before the need for archeological measures. It also has the possibility to be applied in any country, and only requires experience in [molecular] biology for the protocol to be completed. Though future studies need to be explored to account for age, temperature, and other RNA quantification issues, this method has provided evidence of a PMI estimate that may be able to help solve forensic investigations that could not be completed before such an estimate. 


\section{REFERENCES}

1. Goff, M. L. (2009). Early post-mortem changes and stages of decomposition in exposed cadavers. Experimental and Applied Acarology, 49(1-2), 21-36.

2. Madea, B., \& Rödig, A. (2006). Time of death dependent criteria in vitreous humorAccuracy of estimating the time since death. Forensic Science International, 164(2-3), 87-92.

3. Ropohl, D., Scheithauer, R., \& Pollak, S. (1995). Postmortem injuries inflicted by domestic golden hamster: Morphological aspects and evidence by DNA typing. Forensic Science International, 72(2), 81-90.

4. Saukko, Pekka, Bernard Knight. (2004) Knight's Forensic Pathology. 3 Ed. London: Edward Arnold Ltd.

5. VanLaerhoven, S. L. (2008). Blind validation of postmortem interval estimates using developmental rates of blow flies. Forensic Science International, 180(2-3), 76-80.

6. Byrd, Jason H., James L. Castner (2009) Forensic Entomology: The Utility of Arthropods in Legal Investigations. 2 Ed. Boca Raton, FL: CRC Press. p. 367-384.

7. Amendt, J., Campobasso, C. P., Gaudry, E., Reiter, C., LeBlanc, H. N., \& J. R. Hall, M. (2007). Best practice in forensic entomology - Standards and guidelines. International Journal of Legal Medicine, 121(2), 90-104.

8. Buchan, M. J., \& Anderson, G. S. (2001). Time since death: a review of the current status of methods used in the later postmortem interval. Canadian Society of Forensic Science Journal, 34(1), 1-22.

9. Vass AA, Barshick SA, Sega G, Caton J, Skeen JT, Love JC, Synstelien JA (2002). Decomposition chemistry of human remains: a new methodology for determining the postmortem interval. Journal of Forensic Science 47(3):542-553.

10. Johnson, L. a., \& Ferris, J. a J. (2002). Analysis of postmortem DNA degradation by single-cell gel electrophoresis. Forensic Science International, 126(1), 43-47.

11. Hagelberg, E. \& Sykes, B., Ancient bone DNA amplified. Nature, 1989. 342: 485.

12. Hagelberg, E., Thomas, M.G., Sher, A.V., Baryshnikov, G.F., Lister, A.M., DNA from ancient mammoth bones. Nature, 1994. 370: 333-334. 
13. Bauer, M., Gramlich, I., Polzin, S., \& Patzelt, D. (2003). Quantification of mRNA degradation as possible indicator of postmortem interval-a pilot study. Legal Medicine, 5(4), 220-227.

14. Johnston, N. L., Cervenak, J., Shore, a D., Torrey, E. F., \& Yolken, R. H. (1997). Multivariate analysis of RNA levels from postmortem human brains as measured by three different methods of RT-PCR. Stanley Neuropathology Consortium. Journal of Neuroscience Methods, 77(1), 83-92.

15. Bauer, M., Polzin, S., \& Patzelt, D. (2003). Quantification of RNA degradation by semiquantitative duplex and competitive RT-PCR: A possible indicator of the age of bloodstains? Forensic Science International, 138(1-3), 94-103.

16. Anderson, S., Howard, B., Hobbs, G. R., \& Bishop, C. P. (2005). A method for determining the age of a bloodstain. Forensic Science International, 148(1), 37-45.

17. Bauer, M. (2007). RNA in forensic science. Forensic Science International. Genetics, 1(1), 69-74.

18. Gubin, A.N., J.L. Miller. (2001). Human erythroid porphobilinogen deaminase exists in 2 splice variants, Blood 97: 815-817.

19. Chu, Z., A. Wickrema, S.B. Krantz, J.C. Winkelmann. (1994). Erythroid-specific processing of human beta spectrin I pre-mRNA, Blood 84 1992-1999.

20. Levings, P.P, J. Bungert. (2002). The human b-globin locus control region, Eur. J. Biochem. 269: 1589-1599.

21. Sabatini, L.M., T. Ota, E.A. Azen. (1993). Nucleotide sequence analysis of the human salivary protein genes HIS1 and HIS2, and evolution of the STATH/HIS gene family, Mol. Biol. Evol. 10: 497-511.

22. Sabatini, L.M., E.A. Azen. (1989). Histatins, a family of salivary histidine-rich proteins, are encoded by at least two loci, Biochem. Biophys. Res. Commun. 160: 495-502.

23. Steger, K., K.Pauls, T.Klonisch, F.E.Franke, M.Bergmann. (2000). Expression of protamine-1 and -2 mRNA during human spermiogenesis, Mol. Hum. Reprod. 6: 219225.

24. Valore, E.V., C.H. Park, A.J. Quayle, K.R. Wiles, P.B. McCray, T. Ganz. (1998). Human b-defensin-1: an antimicrobial peptide of urogenital tissues, J. Clin. Invest. 101: 16331642 .

25. Gipson, K., S. Spurr-Michaud, R. Moccia, Q. Zhan, N. Toribara, S.B. Ho, A.R. Gargiulo, J.A. Hill. (1999). MUC4 and MUC5B transcripts are the prevalent mucin messenger ribonucleic acids of the human endocervix, Biol. Reprod. 60: 58-64. 
26. Haas, C., Klesser, B., Maake, C., Bär, W., \& Kratzer, a. (2009). mRNA profiling for body fluid identification by reverse transcription endpoint PCR and realtime PCR. Forensic Science International: Genetics, 3(2), 80-88.

27. Bauer, M., D. Patzelt. (2003). Simultaneous RNA and DNA isolation from blood and semen stains, Forensic Sci. Int. 136: 76-78.

28. Alvarez, M., J. Juu sola, J. Ballantyne. (2004). An mRNA and DNA co-isolation method for forensic casework samples, Anal. Biochem. 335: 289- 298.

29. Cassol, S., M.J. Gill, R. Pilon, M. Cormier, R.F. Voigt, B. Willoughby, J. Forbes. (1997). Quantification of human immunode-ficiency virus type 1 RNA from dried plasma spots collected on filter paper, J. Clin. Microbiol. 35: 2795-2801.

30. Abe, K., N. Konomi. (1998). Hepatitis C virus RNA in dried serum spotted onto filter paper is stable at room temperature, J. Clin. Microbiol. 36: 3070-3072.

31. Schoch, R., J. Pitako, P. Schafhausen, S. Jenisch, T. Haferlach, M. Kneba, M. Suttorp. (2001). Semi-quantitative reverse transcription polymerase chain reaction analysis for detection of bcr/ablre arrangement using RNA extracts from bone marrow aspirates compared with glass slide smears after 0,2 and $4 \mathrm{~d}$ of storage, Br. J. Haematol. 115: 583-587.

32. Crisan, D., M.J. Anstett. (1995). Myeloperoxidase mRNA detection for lineage determination of leukemic blasts: retrospective analysis, Leukemia 9: 1264-1275.

33. Zubakov, D., Kokshoorn, M., Kloosterman, A., \& Kayser, M. (2009). New markers for old stains: Stable mRNA markers for blood and saliva identification from up to 16-yearold stains. International Journal of Legal Medicine, 123(1), 71-74.

34. Zhao, D., Zhu, B. L., Ishikawa, T., Quan, L., Li, D. R., \& Maeda, H. (2006). Real-time RT-PCR quantitative assays and postmortem degradation profiles of erythropoietin, vascular endothelial growth factor and hypoxia-inducible factor 1 alpha mRNA transcripts in forensic autopsy materials. Legal Medicine, 8(2), 132-136.

35. Inoue, H., Kimura, A., \& Tuji, T. (2002). Degradation pro ${ }^{\circledR}$ le of mRNA in a dead rat body : basic semi-quanti ${ }^{\circledR}$ cation study. Forensic Science International, 130.

36. Sampaio-Silva, F., Magalhães, T., Carvalho, F., Dinis-Oliveira, R. J., \& Silvestre, R. (2013). Profiling of RNA Degradation for Estimation of Post Morterm Interval. PLoS ONE, 8(2).

37. Zhu, J., Fuhong He, Songnian Hu, and J. Y. (2008). On the nature of human housekeeping genes. Trends in Genetics : TIG, 24(10), 478-81. 
38. Bahar, B., Monahan, F. J., Moloney, A. P., Schmidt, O., MacHugh, D. E., \& Sweeney, T. (2007). Long-term stability of RNA in post-mortem bovine skeletal muscle, liver and subcutaneous adipose tissues. BMC Molecular Biology, 8, 108.

39. Uddin, M. J., Cinar, M. U., Tesfaye, D., Looft, C., Tholen, E., \& Schellander, K. (2011). Age-related changes in relative expression stability of commonly used housekeeping genes in selected porcine tissues. BMC Research Notes, 4(1), 441.

40. Touchberry, C. D., Wacker, M. J., Richmond, S. R., Whitman, S. a, \& Godard, M. P. (2006). Age-related changes in relative expression of real-time PCR housekeeping genes in human skeletal muscle. Journal of Biomolecular Techniques : JBT, 17(2), 157-62.

41. Hsiao, L. L., Dangond, F., Yoshida, T., Hong, R., Jensen, R. V, Misra, J., ... Gullans, S. R. (2001). A compendium of gene expression in normal human tissues. Physiological Genomics, 7(2), 97-104.

42. Duffy, J.B., Skinner, M.F., Waterfield, J.D. (1991). Rates of Putrefaction of Dental Pulp in the Northwest Coast Environment. Journal of Forensic Science. 36: 1492-1502.

43. Young, S. T., Wells, J. D., Hobbs, G. R., \& Bishop, C. P. (2013). Estimating postmortem interval using RNA degradation and morphological changes in tooth pulp. Forensic Science International, 229(1-3), 163.

44. Young, S. T. (2001). RNA in Forensic Science: Novel Techniques for Biological Evidence (Doctoral Dissertation). West Virginia University, Morgantown, WV.

45. Livak, K. J., \& Schmittgen, T. D. (2001). Analysis of relative gene expression data using real-time quantitative PCR and the 2(-Delta Delta C(T)) Methods, 25(4), 402-8.

46. Applied Biosystems. 2008. Guide to Performing Relative Quantitation of Gene Expression Using Real-Time Quantitative PCR.

47. Applied Biosystems. 2008. Real-Time PCR: Understanding CT. Application Note.

48. Bender, K., Farfán, M. J., \& Schneider, P. M. (2004). Preparation of degraded human DNA under controlled conditions. Forensic Science International, 139(2-3), 135-40.

49. Schneider, P. M., Bender, K., Mayr, W. R., Parson, W., Hoste, B., Decorte, R., Greenhalgh, M. (2004). STR analysis of artificially degraded DNA-results of a collaborative European exercise. Forensic Science International, 139(2-3), 123-34.

50. Atsu, S. S., Aka, P. S., Kucukesmen, H. C., Kilicarslan, M. a, \& Atakan, C. (2005). Agerelated changes in tooth enamel as measured by electron microscopy: implications for porcelain laminate veneers. The Journal of Prosthetic Dentistry, 94(4), 336-41. 
51. Ikawa, M., Komatsu, H., Ikawa, K., Mayanagi, H., \& Shimauchi, H. (2003). Age-related changes in the human pulpal blood flow measured by laser Doppler flowmetry. Dental Traumatology. 19(1), 36-40.

52. Lv, Y. H., Ma, K. J., Zhang, H., He, M., Zhang, P., Shen, Y. W., Chen, L. (2014). A Time Course Study Demonstrating mRNA, microRNA, 18S rRNA, and U6 snRNA Changes to Estimate PMI in Deceased Rat's Spleen. Journal of Forensic Sciences, (13), $1-9$.

53. Vogelstein, B., \& Kinzler, K. W. (1999). Digital PCR. Proceedings of the National Academy of Sciences of the United States of America, 96(16), 9236-9241.

54. Hindson, C. M., Chevillet, J. R., Briggs, H. a, Gallichotte, E. N., Ruf, I. K., Hindson, B. J., Tewari, M. (2013). Absolute quantification by droplet digital PCR versus analog realtime PCR. Nature Methods, 10(10), 1003-5. 